\title{
Quantitative Analysis of Motor Behavior in Adults with High Functioning Autism Spectrum Disorder
}

\author{
Thesis submitted for \\ The Degree of M.Sc. in Neuroscience \\ University of Cologne, Germany \\ March, $3^{\text {rd }}, 2020$ \\ By \\ Sebastian Lammers, B.Sc. \\ University of Cologne \\ Matriculation Number 5968062
}

Supervisor I: Prof. Dr. Dr. Kai Vogeley

Supervisor II: Prof. Dr. Peter Weiss-Blankenhorn 



\section{Summary}

Autism spectrum disorder (ASD) is an umbrella term for a range of conditions that share core symptoms such as restricted interests, repetitive behaviors and deficits in social interaction and communication. Motor impairments in ASD have been investigated mainly in children and adolescents. Although the results are equivocal, some researchers proposed motor impairments to be a core symptom of ASD. Research in adults with ASD remains scarce, but existing evidence suggests that an age-related decrease in motor symptoms is likely. In addition, the level of functioning may have an influence on motor skills. In the current project, motion capture technology was used to quantify motor behavior of adults with and without high functioning ASD. Participants were recorded (1) while performing neutral walking movements, and (2) while performing mood-influenced everyday activities. The results show no significant differences in walking movements between participants with or without ASD. In contrast, the results of the mood-influenced movements show significant group differences. Together, these results suggest that general motor skills in adults with high functioning ASD are not impaired, while the production of nonverbal bodily cues is significantly different. These bodily cues carry information (e.g. about mood) that are relevant for nonverbal communication. It has been shown that the recognition of perceived movements increases when movements are more similar to the movements of the perceiver. The current results thus show that the difficulties in nonverbal communication between persons with and without ASD may stem from differences in movement profiles. 


\section{Abbreviations}

ASD

HFA

MENT

MNS

TD
Autism spectrum disorder

High functioning autism

Mentalizing system

Mirror neuron system

Typically developing 


\section{Table of Contents}

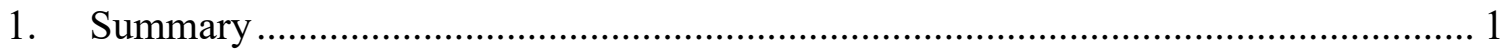

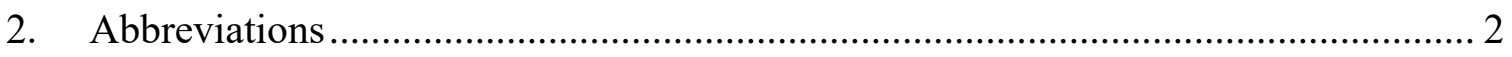

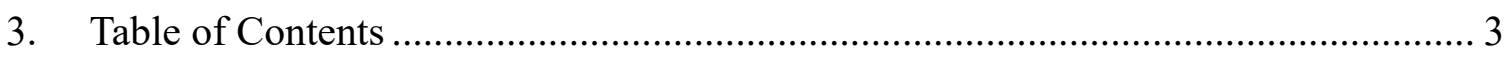

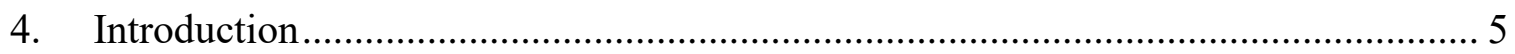

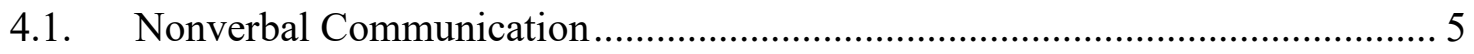

4.1.1. Movement Perception \& Production ............................................................... 5

4.1.2. Attributing Inner States .......................................................................... 6

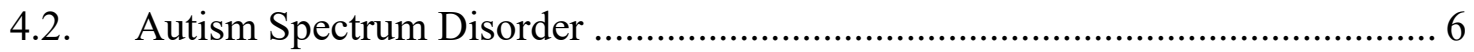

4.2.1. Neuropsychological Theories..................................................................... 7

4.2.2. Movement Impairments in ASD ......................................................... 8

4.2.3. Movement Perception \& Production in ASD ................................................ 9

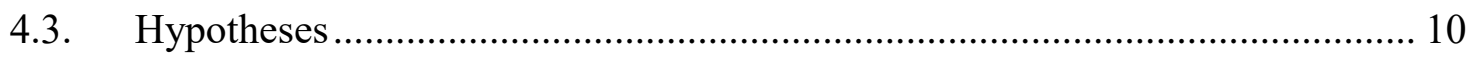

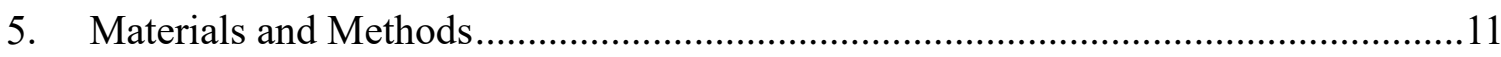

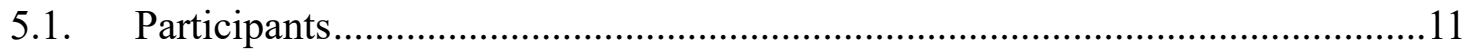

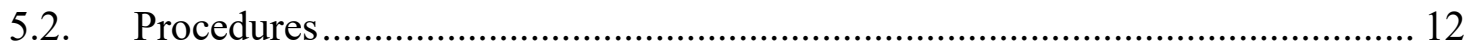

5.2.1. Procedure Experiment One: Gait …………………................................... 12

5.2.2. Procedure Experiment Two: Movement \& Mood........................................... 15

5.3. Motion Capture System ……………………............................................ 15

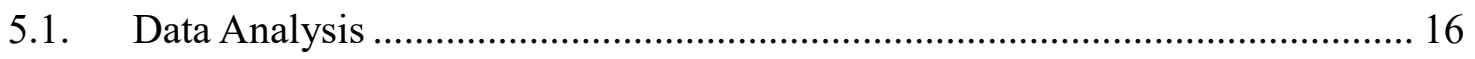

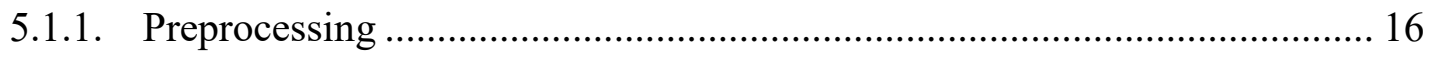

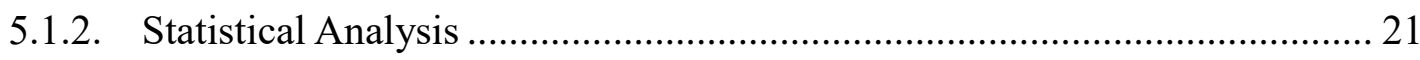

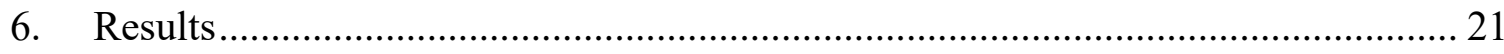

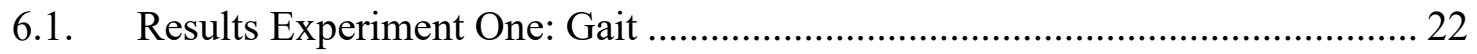


6.2. Results Experiment Two: Movement \& Mood ............................................ 26

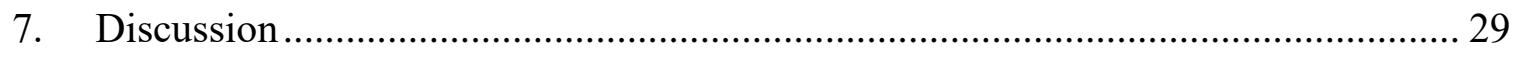

7.1. Discussion Experiment One: Gait.......................................................... 29

7.2. Discussion Experiment Two: Movement \& Mood ........................................ 31

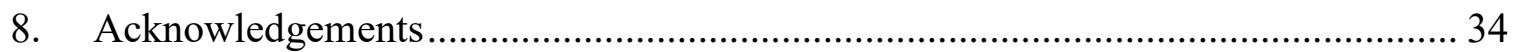

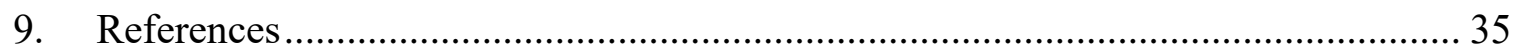

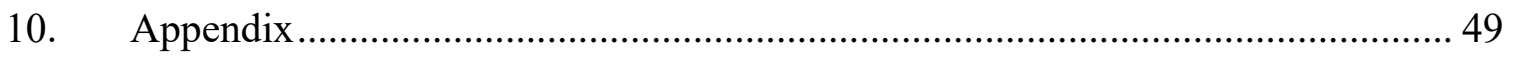

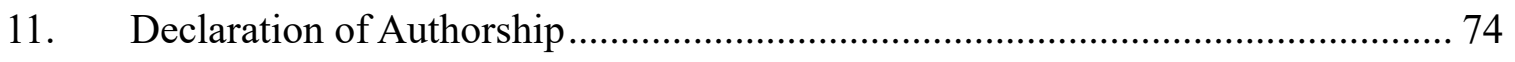




\section{Introduction}

\subsection{Nonverbal Communication}

Nonverbal behavior plays a crucial role in social interactions (Argyle, 1988; Burgoon et al., 2011) and is a major source of information when inferring about another person's inner state (App et al., 2011; C. D. Frith \& Frith, 2012; Wallbott, 1998). These information are gathered from different channels, which include facial expressions, gaze behavior, gesture and body language like posture and whole-body movement (Argyle, Salter, Nicholson, Williams, \& Burgess, 1970). Counter to intuition, bodily cues sometimes carry more information than facial expressions (Aviezer et al., 2012). The importance of nonverbal cues is estimated to be at least as important as verbally transmitted information (Argyle, 1988; Burgoon et al., 2011).

The production and perception of nonverbal signals are trained from the moment of birth (Nagy, 2006). Thus, the use of gaze cues and gestures as a means of communicating are learned by imitation long before verbal language skills are acquired (Meltzoff \& Moore, 1977; Nagy, 2006). This indicates the deeply rooted importance of nonverbal communication for humans that is used seemingly effortlessly during everyday encounters with conspecifics. This further suggests that motor impairments or developmental delays in newborns that hinder nonverbal communication may have severe effects on the ability to successfully master social interactions in later life.

\subsubsection{Movement Perception \& Production}

Not only the execution of movements, but also the perception thereof involves parts of the brains' motor system. This phenomenon is known since the seminal studies in the lab of Rizzolatti, which coined the term mirror neuron for neurons in the premotor cortex of the monkey brain (di Pellegrino et al., 1992; Gallese et al., 1996). The mirror neurons of the macaque monkey were discovered to be firing both when executing a grasping-movement, as well as when observing a grasping-movement. Research suggests that humans also use an analogous mirror neuron system (MNS) during action observation and execution (cf. these meta-analyses: Caspers et al., 2010; Molenberghs et al., 2012). In contrast, more far-reaching theories about the importance of the MNS in the sophisticated task of action understanding, have been a subject of heavy debates (Caramazza et al., 2014; Hickok, 2009, 2014).

The human MNS seems to be especially tuned to the observation, recognition and imitation of actions that are similar to ones' own motor repertoire: one study showed that observing an action 
made by another human, but not by a robot, had an interfering effect on the execution of movements of the observer (Kilner et al., 2003). This proved also true on a more detailed scale, where the imitation of observed movements was better for movements that were more similar to the movements of the observer (Kilner et al., 2007). A similar effect was found on the neural level, where the brain activity in MNS regions increased as participants learned a new set of movements they were initially unfamiliar with (Cross et al., 2006). Interestingly, this phenomenon even extends to the recognizability of movements: the more similar participants' movements were to observed movements, the better their visual recognition of those movements (Casile \& Giese, 2006).

\subsubsection{Attributing Inner States}

Social neuroscience has identified essentially two systems recruited consistently during social information processing: the MNS and the mentalizing system (MENT; also referred to as Theory of Mind System) (Alcalá-López et al., 2018). The concept of mentalizing was established to refer to the ability to predict and explain the inner state of other humans, including their emotions, intentions, and beliefs (C. D. Frith \& Frith, 2006; U. Frith et al., 1991). In typically developing (TD) individuals, inferences about the mental states of conspecifics are made automatically, most of the time unconsciously, in everyday social interactions. On a neural level, MENT is systematically activated when deducing inner states from human motion (Blake \& Shiffrar, 2007; de Lange et al., 2008; Geiger et al., 2019; Spunt et al., 2010, 2011; Spunt \& Lieberman, 2012a, 2012b; Troje, 2013).

Vogeley (2017) proposed the interplay between MNS and MENT to be divided into detection and evaluation, where the MNS serves the detection of bodily signals and the MENT serves the evaluation of inner states of the observed individual(s) (Vogeley, 2017). This theory was recently corroborated by a study showing the fundamentally distinct roles of MNS and MENT during social information processing (Geiger et al., 2019).

\subsection{Autism Spectrum Disorder}

Individuals with autism spectrum disorder (ASD) display difficulties in everyday social interactions. ASD is a broad term covering a range of neurodevelopmental conditions that share core symptoms such as restricted interests, repetitive behaviors and deficits in social interaction 
and communication (American Psychiatric Association, 2013). The prevalence of ASD in developed countries is estimated to be at least 60 per 10000 (Newschaffer et al., 2007). Males are reported to be affected four times more often than females (Fombonne, 2009). The understanding of the etiology of ASD is still at an early stage, with comparable little understanding of the underlying genetics and the interplay with environmental factors (Chaste \& Leboyer, 2012).

Autistic individuals with an IQ of 70 or higher can be classified into the group of high functioning autism (HFA). This group is of special interest to research in social cognition, because difficulties in social interactions dominate the clinical picture of HFA. Effects of impaired intelligence or verbal abilities are negligible and the difficulties in social interactions and nonverbal behavior can be studied in a less distorted way.

\subsubsection{Neuropsychological Theories}

Several neuropsychological theories have been proposed to model the linkage between brain structures and behavior in ASD. The three most discussed theories are briefly presented in the following sections.

Impairments in mentalizing are constantly reported in ASD, which led to the proposal that these restrictions may be the core symptom that is shared across the various phenotypes of the autism spectrum (U. Frith et al., 1991). Difficulties in mentalizing are among the most common findings in ASD research (Baron-Cohen, 2001; Baron-Cohen, Leslie, \& Frith, 1985; Fishman, Keown, Lincoln, Pineda, \& Müller, 2014; U. Frith et al., 1991; Libero et al., 2014; Velikonja, Fett, \& Velthorst, 2019).

Executive functions refer to a set of mental processes such as planning, working memory, cognitive flexibility, and inhibition (Diamond, 2013). These processes are needed in situations where complex, goal-oriented behaviors are used, when simply relying on instincts or intuition would be insufficient or even ill-advised (Espy, 2004; Miller \& Cohen, 2001). Evidence of impairments in the range of executive functions, like inhibition, cognitive flexibility, or generativity have been repeatedly reported in ASD (for a review, see Hill, 2004).

Central coherence refers to the tendency of TD children and adults to process information as a whole or gestalt form, often at the expense of details (Uta Frith, 1989). In contrast, the weak coherence theory by Frith (1989) posits that individuals with ASD show a processing bias towards featural and local information, at the expense of the bigger picture. More recent developments in 
research have led to a shift in the understanding of weak coherence in ASD with an emphasis on superiority in local processing as opposed to a deficit in global processing (Happé \& Frith, 2006).

A recent meta-analysis suggests that neither of the three constructs described above is likely to have enough explanatory power by itself to account for the development of social functioning in ASD (Bottema-Beutel et al., 2018).

\subsubsection{Movement Impairments in ASD}

Impairments in the social domain in ASD dominate the public view and are a major focus of scientific explorations. But descriptions of movement abnormalities are neglected although first observations in ASD date back to the original reports on autistic children by Kanner and Asperger. Kanner noted early signs of motor abnormalities (Kanner, 1943), while Asperger described clumsy and uncoordinated generalized motor skills (Asperger, 1944). Since then, body movements in ASD have been often described by clinicians as clumsy, but quantitative assessments remain scarce.

The first study to quantify movement parameters in ASD found autistic children to have reduced stride lengths (Vilensky et al., 1981). The inspection of walking and earlier forms of locomotion (e.g. crawling) have been of major interest to researchers in this field, as it is a form of spontaneous motor behavior that can be easily assessed in qualitative or quantitative measures. Unfortunately, the approaches to measure gait have been used in fundamentally different ways, which aggravate comparisons in addition to the heterogeneous groups of participants, ranging from toddlers to adults, and from high functioning to low functioning autistic subjects. One review of gait abnormalities in autistic children emphasizes the inconsistencies of results, but reports the most common atypicalities as increased step width and decreased stride length (Kindregan, Gallagher, \& Gormley, 2015). In adults, one study found no differences in quantitative gait parameters between ASD and TD (Hallett et al., 1993), whereas two recent studies report slower walking speed in the ASD group (Armitano et al., 2020; Morrison et al., 2018).

Other findings include differences in postural control (Minshew et al., 2004), slower armmovements in goal-directed tasks (Stoit et al., 2013), and abnormal fine motor control (handwriting) with associated atypical biomechanical strategies (Johnson et al., 2013)

Some researchers proposed body movement impairments to be a fundamental aspect of ASD and a potential biomarker for diagnosis (Cook et al., 2013; Donnellan et al., 2013; Fournier et al., 2010; Leary \& Hill, 1996; Parma \& de Marchena, 2015; Teitelbaum et al., 1998). However, 
the results of studies across the lifespan and across the range of autism as a spectrum are equivocal (Biffi et al., 2018; Chester \& Calhoun, 2012; Hallett et al., 1993; Manicolo et al., 2019; Rinehart, Tonge, Bradshaw, et al., 2006).

To date, most studies have been carried out in children and adolescents, leaving quantitative movement experiments in autistic adults an understudied area. Combined with results that indicate an age-dependent decrease of motor impairments (Manicolo et al., 2019; Minshew et al., 2004), this justifies the question of whether motor impairments are persistent throughout the lifespan of autistic people. Here, we investigated whole-body movements in a quantitative manner using motion capture technology, comparing neutral walking in autistic and TD adults. Motion capture systems offer unique opportunities to accurately measure body movements in three spatial dimensions over time. For an overview of different capturing technologies and exemplary analysis approaches see Poppe et al. (2014). Details about the motion capture system used in the current study and the analysis approach can be found in the methods section below.

\subsubsection{Movement Perception \& Production in ASD}

Studies suggesting the MNS to be impaired in ASD (Iacoboni \& Dapretto, 2006; Oberman et al., 2005), have been largely falsified (Dinstein et al., 2008; Hamilton, 2008, 2013; Marx, 2018). A recent study found participants with ASD to have difficulties in MENT- but not in MNS-related parts of a novel paradigm (Marx, 2018). The paradigm used by Marx was developed to specifically activate MNS and MENT with as little differences between conditions as possible (Lammers, 2017; Lammers et al., 2019). It utilizes motion capture based animations of two everyday activities (mopping, sweeping), each carried out in two moods (angry, happy). All animations used the same neutral wooden mannequin without a tool visible in hands (see Fig. 1). The participants' task was to recognize either the mood or the activity of the current video. The paradigm has been successfully used before to demonstrate the fundamentally distinct roles of MNS (recognition of activity) and MENT (recognition of mood) in social information processing in TD subjects (Geiger et al., 2019). In Marx' study, for the first time, subjects with ASD assessed those stimuli and the results suggest that subjects with ASD performed comparable to TD in the MNS-part, but show more uncertainty in the MENT-related part. This uncertainty was possibly caused by limiting the answering time to three seconds. Participants with ASD had more unanswered trials than TD and the highest rate of unanswered trials was found in the MENT-related trials. Not the recognition of 
the activity (What is the person doing?) was hard for subjects with ASD, but the mood recognition (How is the person doing it?). In consequence, this raises the question whether subjects with ASD, that are impaired in the perception of mood-influenced movements, are also impaired in the production of mood-influenced movements. Here, we recorded the same movements as used in Marx (2018) and Geiger et al. (2019), focusing on the same activities (mopping, sweeping) in combination with the same moods (angry, happy) to test whether there are quantitative differences in the production of mood-influenced body movements between ASD and TD (see Procedure Experiment Two for details).

\subsection{Hypotheses}

As possible replications of results in general walking parameters such as reduced walking speed and reduced stride length in ASD we hypothesized:

Hla: Persons with autism will walk slower than typically developing individuals.

H1b: Persons with autism will make smaller strides than typically developing individuals.

In addition, we hypothesized that there might be a difference in walking patterns depending on the goal of the walking activity. We therefore established three different conditions with varying goals. The goal was either to a) fetch an object ("Please walk across the room to fetch the tools you see standing there."), b) walk until a marked spot with another person present in the target area, or c) walk until the marked spot with neither person nor object present (for details, see Procedure Experiment One: Gait and Fig. 2). We hypothesized there be an effect in ASD subjects, when walking towards a person.

H2: Persons with autism will walk slower, when walking towards another person.

We further hypothesized walking in both ASD and TD to be fastest, when walking towards an object (fetching the object).

H3: Participants will walk fastest when walking towards a concrete goal (object). 


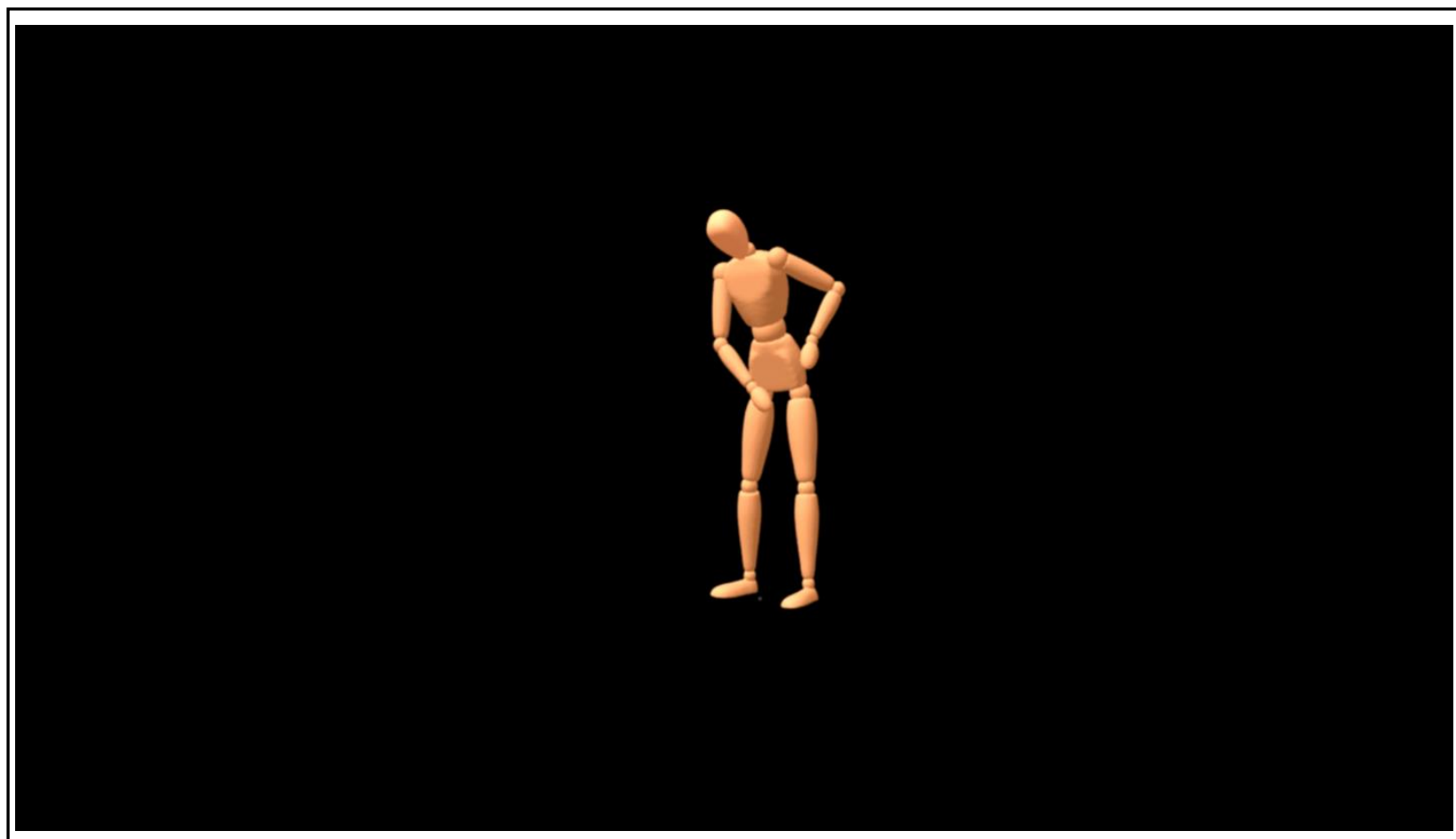

Fig. 1. Standstill example from the stimulus material of Lammers et al., 2019.

Lastly, as suggested above, we hypothesized that ASD subjects would perform moodinfluenced movements with less expressiveness, measurable in velocity and acceleration.

H4: Persons with autism will move slower than typically developing individuals when executing mood-influenced everyday movements.

\section{Materials and Methods}

\subsection{Participants}

Fourteen participants with ASD (aged $21-60$; mean $=45.07, \mathrm{SD}=11.95 ; 4$ identifying as female, 10 as male) and twenty-seven TD subjects (aged $22-58 ;$ mean $=37.48, \mathrm{SD}=10.39 ; 10$ identifying as female, 17 as males) were included in the study. ASD subjects were diagnosed and recruited at the Autism Outpatient Clinic of the Department of Psychiatry, University Hospital Cologne, Germany. TD subjects were recruited via mailing lists or publicly visible notices. All participants gave their written informed consent and were compensated for their participation (10€ per hour). This study was approved by the ethics committee of the Medical Faculty of the 
University of Cologne, Germany, and strictly adhered to the Declaration of Helsinki and the Principles of Good Scientific Practice.

\subsection{Procedures}

To match the two groups, we assessed intelligence using a multiple choice vocabulary test for verbal intelligence, Wortschatztest (Schmidt \& Metzler, 1992), which is known to give a valid and time-effective estimate of language proficiency (Lehrl et al., 1995; Satzger et al., 2002). To estimate comorbidities, participants completed the Beck Depression Inventory (Hautzinger et al., 2009) and the 20-Item-Toronto Alexithymia Scale (Bagby et al., 1994). We administered the Autism Spectrum Quotient, a 50-item questionnaire designed to assess autistic traits in the general population (Baron-Cohen et al., 2001), as well as the Empathy Quotient (Baron-Cohen \& Wheelwright, 2004), a 60-item questionnaire developed to measure behavioral, cognitive and affective aspects of empathy. Lastly, we administered the Positive And Negative Affect Schedule (Watson et al., 1988), developed for self-assessment of emotional states, and a demographic questionnaire (see Table 1 for a summary).

After completing the questionnaires, the motion capture sensors were attached and the system was calibrated. The subsequent motion capture recordings were split in two experiments of which only one was explicitly declared as motion capture recording at the time. The first experiment was declared a part of the calibration process (see section 5.2.1 for a detailed description), while the second experiment was declared the "actual experiment" utilizing motion capture technology.

a) In Experiment One, natural gait movements were recorded in three different conditions. (Declared as calibration process.)

b) In Experiment Two, mood-influenced everyday movements were recorded.

(Declared as motion capture recordings.)

\subsubsection{Procedure Experiment One: Gait}

During the whole time, two experimenters were present. One experimenter carried out the technical procedures, the other interacted with the participants. To obtain gait movements that were carried out as natural as possible, participants were instructed that it would be necessary for them to produce some sample movements. Thus, after the motion capture sensors were put in place and 
Table 1 Demographic and Neuropsychological Data

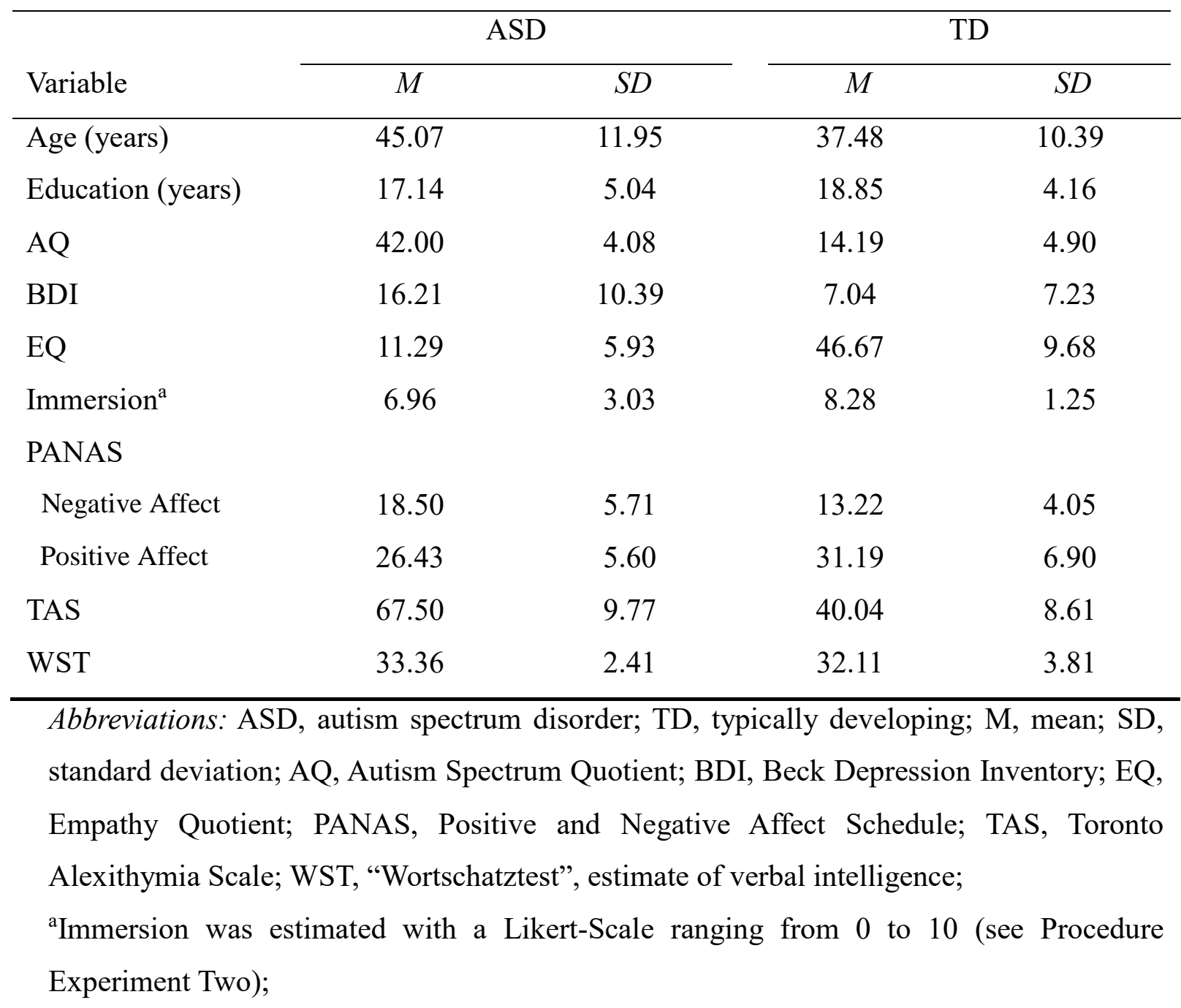

calibrated, participants were asked to walk across the room to test calibration and fine-tune technical parameters. The subjects were not told that the movements would be already recorded at this point in time of the procedure. After finishing the experiment, participants were informed about the true nature of this part of the experiment.

The cover story was structured so that all subjects walked through the room towards a target area and back to the starting point three times (distance: approximately 9 meters), each time however with different instructions (for a graphical representation of these three conditions, see Fig. 2). First, participants were asked to walk across the room to fetch both the broom and the mop 


\title{
The three Conditions of the Gait-Recordings
}

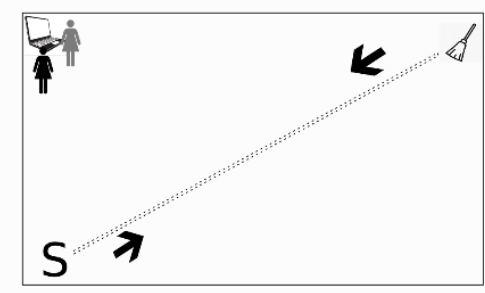

\author{
1. get object
}

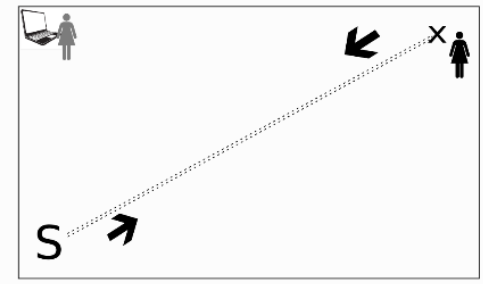

\section{2. walk to point $x$ and back (person present)}

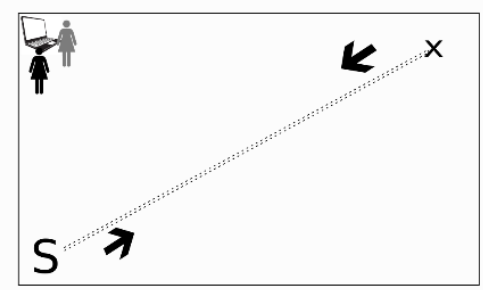

\section{3. walk to point $x$ and back (no person present)}

Fig. 2. Illustration of the gait-recordings and its three conditions. The small rectangle depicts the floor plan of the room in which the experiment took place. Subjects walked from one corner of the room to the other corner diagonally opposite in each condition. Two experimenters were present for the whole duration of the experiment. One (depicted in grey) remained at the computer, while the other interacted with participants during condition two. More details are given in the text (see Procedure Experiment One). $S=$ starting point; $x=$ turning point;

that were standing in the target area and bring it back to the starting point. Participants were told these tools were needed for the "actual" recordings that were to follow after the calibration process. Second, one of the experimenters walked into the target area and pointed out that there was a marked spot on the floor. Participants were asked to walk to that spot, turn around there, and walk back to the starting point. The experimenter remained in the target area, but took notes on a clipboard and did not establish eye contact with participants. Third, participants were asked to 
walk to the marked spot in the target area and back again, but this time the target area was empty. During all three conditions one experimenter pretended to change some parameters of the motion capture software in order to improve the transmission quality. After completing the three conditions the experimenter told the participants that everything looked fine, so the actual recording of movements would now be possible.

\subsubsection{Procedure Experiment Two: Movement \& Mood}

The following four recordings consisted of two activities (mopping, sweeping) that were carried out in two moods (angry, happy), constituting a 2x2 factorial design. The order of the four different conditions was pseudorandomized. Participants were asked to stand on a marked position, listen to a pre-recorded audio instruction and then start sweeping or mopping until the experimenter told them to stop. The experimenter stopped the recording after approximately 25 seconds of mopping/sweeping. Audio instructions included an Imagination Mood Induction Procedure that asked participants to imagine an event that would make them really happy (or angry respectively). Every motion capture recording was preceded by a dedicated audio instruction. The recordings were divided in two blocks, so that after completing the first two recordings in the same mood, participants sat down at a desk and answered some questions concerning the level of immersion (How well were you able to empathize with the required feeling?; German: Wie gut konnten Sie das von Ihnen geforderte Gefühl nachempfinden?) and what type of situation they imagined. They watched a relaxation-video to neutralize the mood (showing a tree and including relaxing music). Afterwards, the remaining two recordings (in the other mood) were completed. Level of immersion and the associated situation were assessed again. The experiment ended with a questionnaire that estimated how comfortable participants were wearing the sensors and additionally a free text field asking subjects what their idea about the point of the study was. Finally, there was a short written debriefing that informed about the goal of the project.

\subsection{Motion Capture System}

Body movements were recorded with the Perception Neuron V1 motion capture system (Perception Neuron, Noitom, Miami, FL, USA). The system consists of inertial measurement units that are placed in predefined positions on the body with up to 32 sensors per user (see Fig. 3). For 


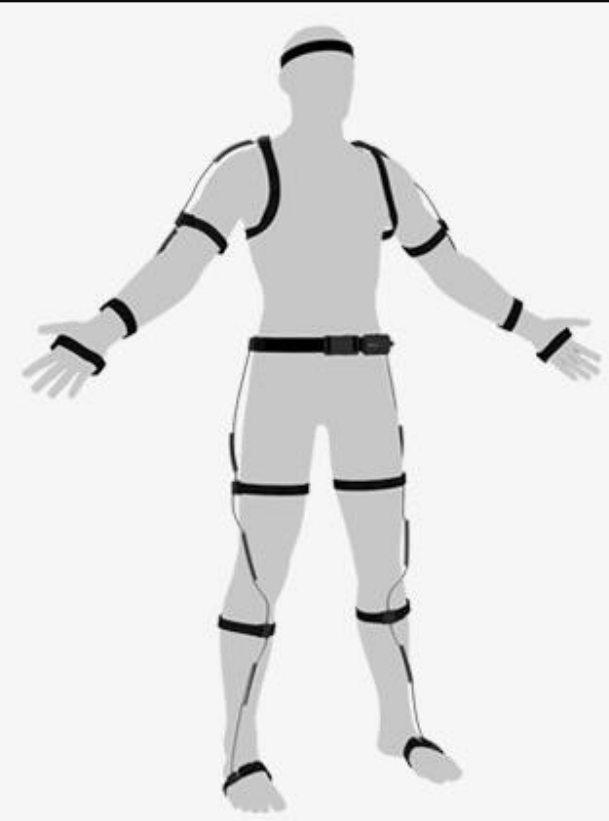

Fig. 3. Schematic depiction of the Perception Neuron motion capture system. Data from the sensors were transferred wirelessly to a laptop running the recording software. Whole-body movements were recorded without tracking individual fingers.

this study, 17 sensor units were utilized to capture the whole-body movements of the participants without tracking finger-movements. The data of these sensors were transmitted wirelessly to a dedicated computer and recorded via the software Axis Neuron as provided by the manufacturer of the motion capture system (Axis Neuron, Noitom, Miami, FL, USA). The sampling rate of the sensors was $120 \mathrm{~Hz}$.

\subsection{Data Analysis}

Raw motion capture data were converted to tabular form and exported as text-files from the recording software. All subsequent steps were implemented using the statistical programming language R (R Core Team, 2019) and the interactive development environment RStudio (RStudio Team, 2018).

\subsubsection{Preprocessing}

Gait-recordings were preprocessed using a newly developed algorithm that evaluated the following aspects of each recording (a detailed description follows below): 
1. Start and end of gait-movements (in contrast to e.g. waiting beforehand)

2. Detection of three phases of walking (acceleration, steady-state walking, deceleration)

3. Direction of walking (towards the target area, towards the starting point)

4. Number of steps

5. Stride length per step

6. Duration of each stride

\section{Details of the Gait-Preprocessing-Pipeline}

Details of the preprocessing procedure are described for one exemplary file below. Before the preprocessing algorithm was applied, all recordings had been exported in tabular text format from the motion capture recording software.

After reading in the raw data from the text-file, the participant ID, group (ASD vs. TD), and gait-condition were extracted from the filename. These information were added to the metadata of the recording data to later relate data to participant ID. Next, the variable names as chosen by the software engineers of the motion capture software were changed to be a) more humanreadable (e.g. "right_foot" instead of “04") and b) compatible for data analysis (no use of hyphens). The raw data included variables for 21 body parts and for each body part the following five categories of data: spatial displacement, velocity, acceleration, quaternion, and angle velocity. Since the direction of movements in three dimensional space were not investigated, the variables of interest were condensed from three separate directions (x, y, z) into combined global acceleration and velocity. All signals were smoothed with a Butterworth-filter (third order, cutoff at 0.1 ) to remove high-frequency noise.

One of the central features to investigate in human gait is called stride. A stride is defined as a sequence of movements during gait in which one foot contacts the ground until the same foot contacts the ground again (see Fig. 4 for illustration). To detect individual strides in the data, the following steps were taken. First, the difference between the velocity of the left and right foot was calculated to detect where these two antagonistic curves intersect (see Fig. 5). Then the exact time points of these intersections (segment borders) were calculated, leaving instances out that occurred within 10 frames to remove the segment borders of some high frequency oscillations. Next, the 


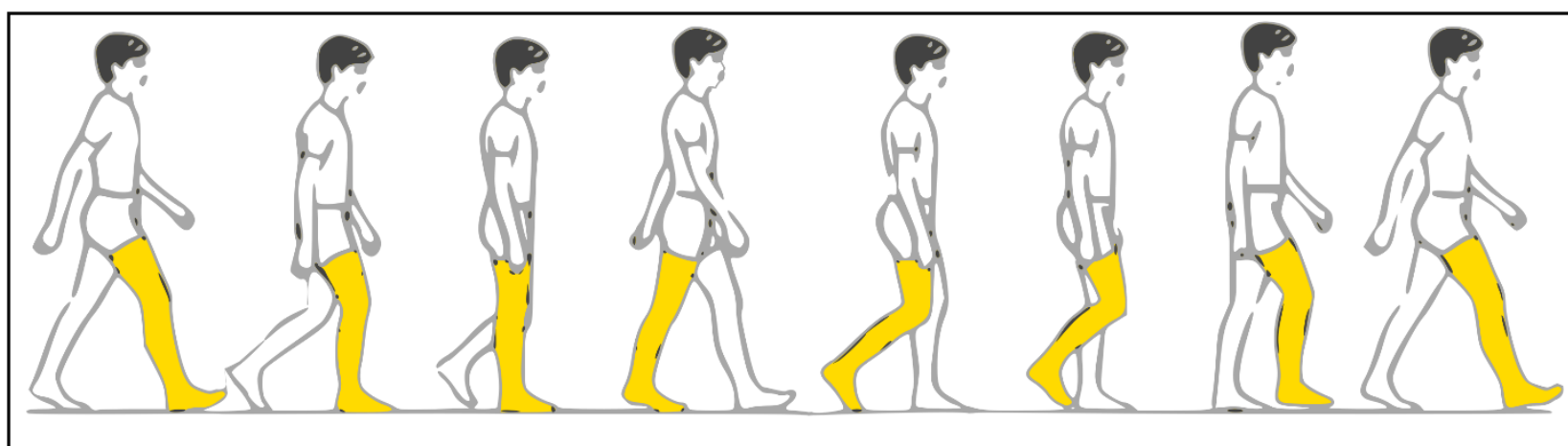

Fig. 4. Illustration of one complete stride (also referred to as gait cycle) of the right leg. The stride length was computed as the distance between the same foot before and after completing one gait cycle. Illustration modified from Pirker \& Katzenschlager (2017).

positions of peaks were detected in the filtered signals. Together with the segment borders, the peaks were then used as the basis of a more fine-grained analysis (separately for left and right side).

For each segment border, the algorithm computed if there was a peak detected between the current and the next segment border. If there was indeed a peak, then it was counted as a valid stride in the walking pattern of the participant and several other details were inspected: if more than one peak was found in the current segment, then only the highest was classified as the current peak. The stride length (how far one foot moves in one stride, cf. Fig. 4) was estimated as the spatial displacement of the respective foot at the beginning of the segment subtracted from the spatial displacement at the end of the segment. Stride time was estimated in a similar fashion, by subtracting the frame number at the beginning of the segment from the frame number at the end of the current segment (temporal resolution: 120 frames per second). Skew and kurtosis of the current curve segment were calculated, as well as the amplitude to be able to analyze geometric curve progression. The current peak was compared to the previous one to estimate overall tendencies of the curve. The absolute difference between the peaks was computed as well as the relative percentage difference. If the relative difference was below 10 percent, then the current curve segment was labelled as "steady state". This indicated a stable walking pattern, where the velocity stayed in a similar range. In contrast, if the relative percentage difference was larger than 10 percent, then the current curve segment was either labelled "acceleration" or "deceleration". A negative relative difference occurred when the current peak had a lower value than the previous 


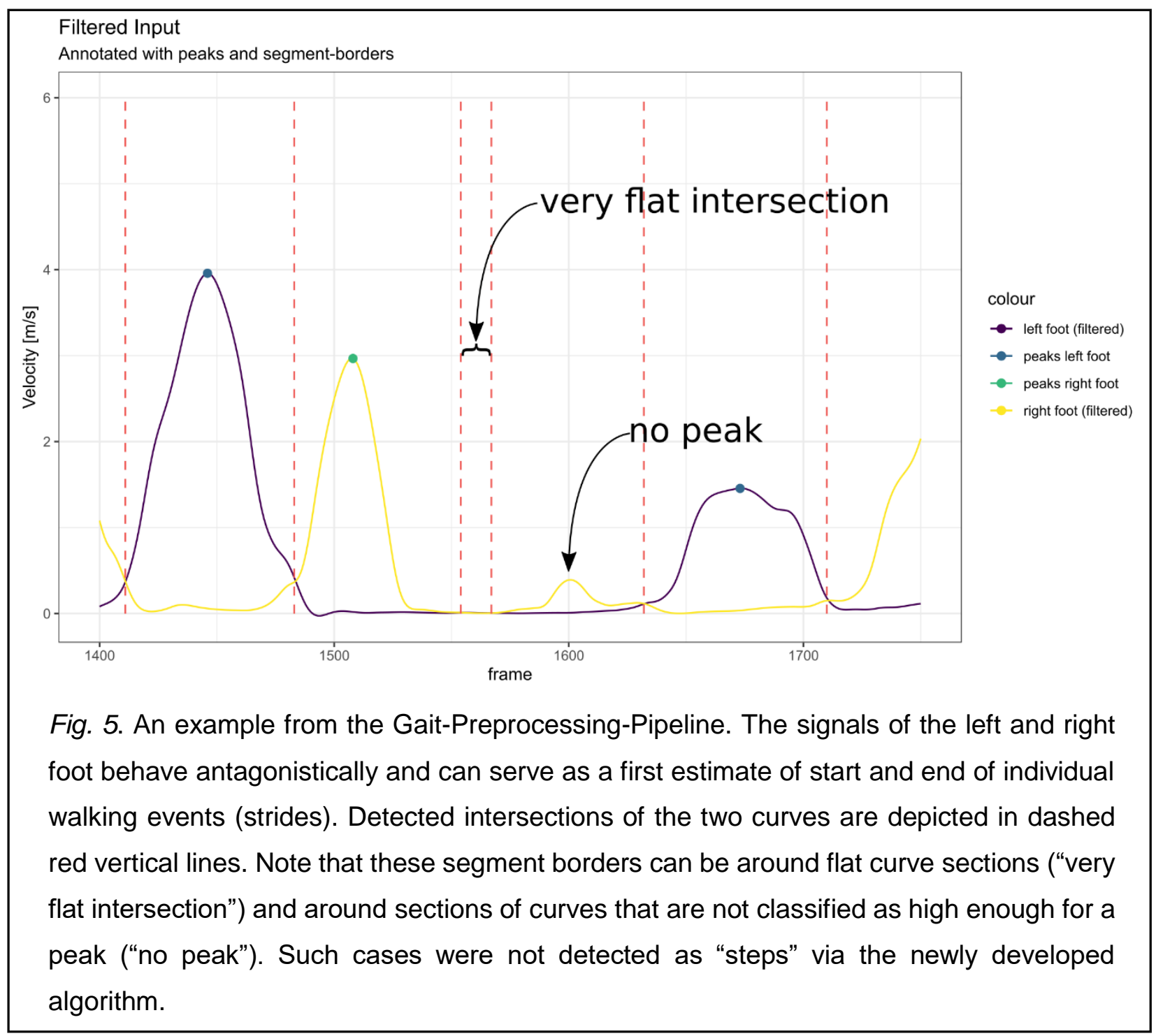

peak, which was labelled as "deceleration". Consequently, a positive relative difference larger than 10 percent was labelled as "acceleration". Note that this difference was a relative difference and thus adapted to unique walking patterns of individual participants. This important preprocessing step allowed to later include only those parts of recordings, where subjects were walking in their own "steady state" (for a graphical example, see Fig. 6). Lastly, the algorithm detected the direction of walking: participants always started walking from the same starting point (cf. Fig. 2). The motion capture software was programmed so that moving away from the starting position would increase the spatial displacement parameters. In our case, this meant that the spatial displacement would initially display values around 0 and increase until the target area was reached. Since this area was approximately 9 meters from the starting point, all spatial displacement parameters 


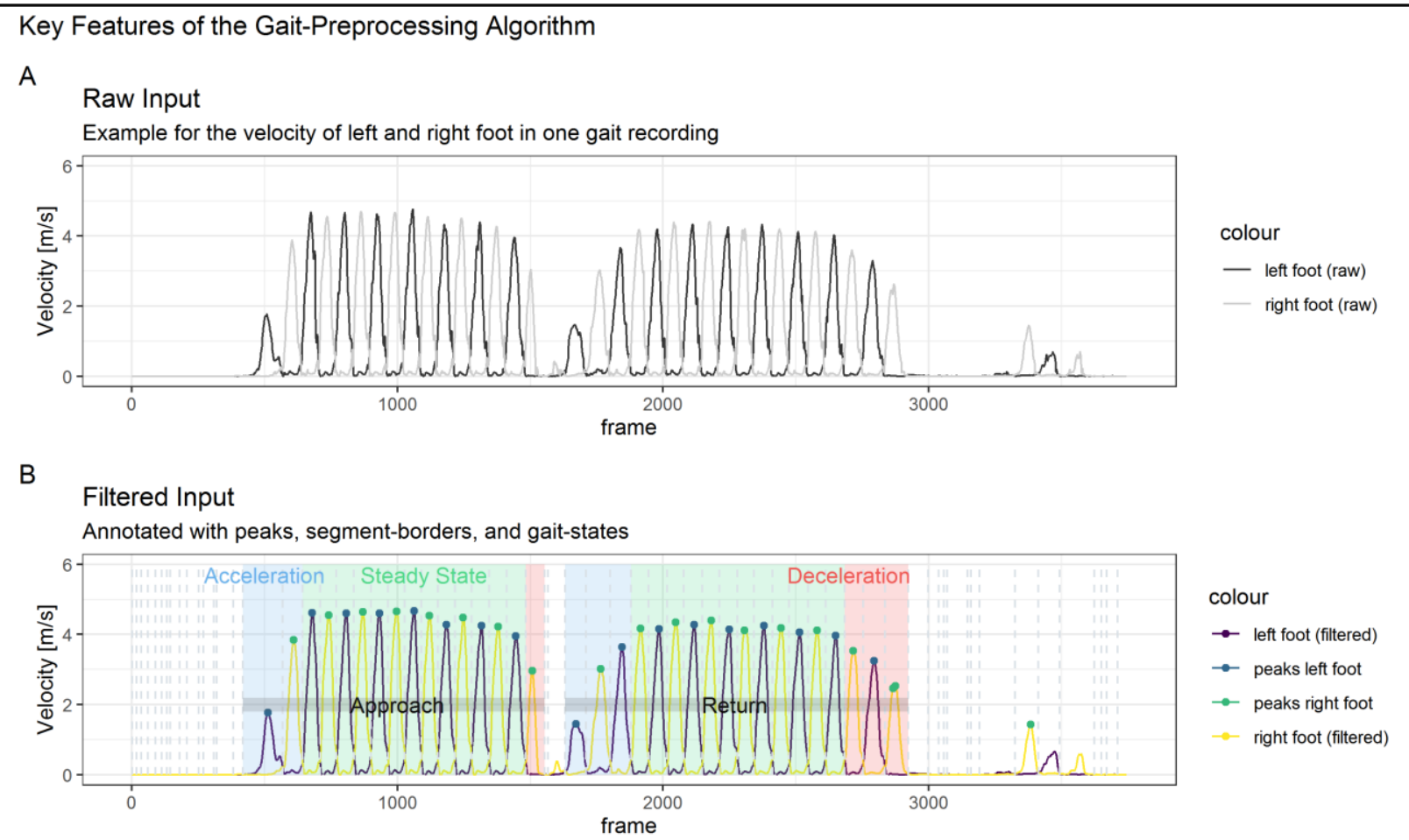

Fig. 6. A graphical summary of the key features of the gait-preprocessing algorithm. In the top row $(A)$ the raw signals of one gait-recording are depicted (only left and right foot). In the bottom row $(B)$ the results of the preprocessing algorithm are shown for the same data. Key features include:

- Filtering

- Detection of peaks

- Segmentation via curve-progression (segment-borders depicted as dashed vertical lines)

- Classification of gait-state (acceleration, steady state, deceleration depicted as colored shading)

- Detection of walking-direction (approach, return)

increased to numbers close to 9 and then started to decrease when the subjects walked back to the starting position. This change in spatial displacement was used to detect the turning point and label the strides from the starting point to the target area as "approach", while the way back to the starting point was labeled "return". This way, the two different sections of each gait recording could programmatically be distinguished (cf. Fig. 6). 
The other recordings (Experiment Two: Movement \& Mood) were preprocessed with another newly developed algorithm that evaluated the start and end of relevant movements (in contrast to e.g. waiting beforehand). This preprocessing procedure allowed to filter out only relevant data points, excluding irrelevant sequences that would otherwise distort the statistical analysis. The source code of all relevant functions that were developed for this analysis can be found in Appendix A.

\subsubsection{Statistical Analysis}

Effects of ASD diagnosis and experimental conditions (independent variables) on quantitative movement parameters (dependent variables) were assessed with linear mixed effects models, as recommended for data from repeated measures designs (Pinheiro \& Bates, 2009) via the lme4 package (Bates et al., 2015). All models included random intercepts for participants. The used variables are reported for each model in the respective results section. Likelihood ratio tests were used to infer the general influence of independent variables by comparing how well models including different independent variables fit a given data set while penalizing model complexity. The significance of the effect of each independent variable was tested by comparing a model including the independent variable with the same model without the independent variable against a significance level of .05. Where likelihood ratio tests revealed significant effects of independent variables, post hoc tests were conducted via the glht()-function from the multcomp package (Hothorn et al., 2008) while correcting for multiple comparisons.

Although data for 21 body parts were available, the present analysis was deliberately restricted to four: both hands and both feet. This was decided to make the analysis clearer and to limit the possible influence of false-positive findings in case of multiple testing.

\section{Results}

Using motion capture, we quantified whole-body movements of persons with and without ASD. In Experiment One, we recorded walking movements. In Experiment Two, we recorded mood-influenced everyday activities. Data were analyzed using linear mixed effects models with random intercepts for participants. After identifying the model with the best fit without including interaction terms, it was tested if including interactions between the dependent variables would further increase model fit while penalizing model complexity. Here, in the results section, only 
significant interactions are reported. Non-significant interaction effects, as well as the reported significant main and interaction effects can be found in tabular form in Appendix B.

\subsection{Results Experiment One: Gait}

The following dependent variables were analyzed for the gait-recordings:
a) stride length (distance between the same foot before and after completing a gait cycle, see Fig. 4)
b) stride time (duration of each stride)
c) velocity (of left foot and right foot)
d) acceleration (of left foot and right foot)

The following independent variables were tested for their effect on the respective dependent variable:
a) walking-direction (towards target area vs. starting point)
b) gait-condition (see Fig. 2)
c) diagnosis (ASD vs. TD)

We found no significant influence of diagnosis on any of the dependent variables of the gait recordings. The gait-conditions however, showed the most consistent influence on the dependent variables.

\section{Stride Length}

Likelihood ratio tests between a null model (including only the intercept) and more complex models (including one or more of the independent variables) suggested that stride length was significantly affected by walking-direction $\left(\chi^{2}(1)=9.26, p<.01\right)$ and gait-condition $\left(\chi^{2}(2)=\right.$ $7.41, p=.02)$. Including diagnosis did not improve the model fit significantly $\left(\chi^{2}(1)=3.71, p\right.$ $=.05)$, thus suggesting to have no influence on stride length. Post hoc tests revealed that subjects made significantly smaller strides when returning to the starting point $(M=-.03, S E=.01, z=$ $3.06, p<.01)$ and in gait condition two $(M=-.03, S E=.01, z=-2.63, p=.03)$. Stride length was not significantly different in gait-condition three $(M=-.01, S E=.01, z=-.70, p=.91)$. 


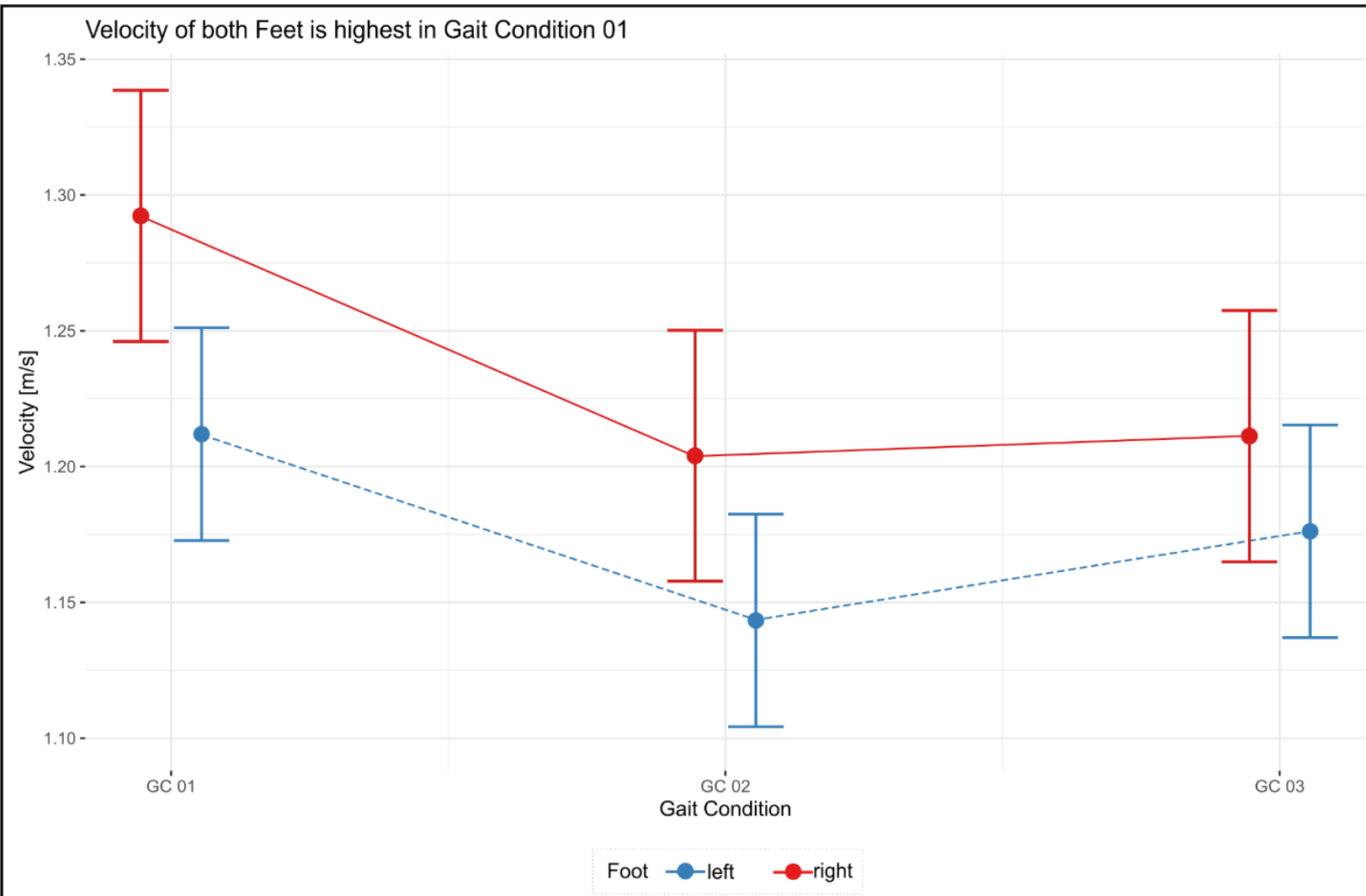

Fig. 7. Shows estimated means according to the linear mixed effects model. Error bars indicate the $95 \%$ confidence intervals. The velocity of both feet was highest in gait-condition one and lowest in gait-condition two.

\section{Stride Time}

Like for stride length, model fit for stride time data was significantly improved when including walking-direction $\left(\chi^{2}(1)=5.48, p=.01\right)$ and gait-condition $\left(\chi^{2}(2)=26.20, p<.001\right)$, but not diagnosis $\left(\chi^{2}(1)=1.03, p=.31\right)$ as independent variables. However, in post hoc tests walking-direction did not reach significance $(M=.79, S E=.33, z=2.39, p=.06)$. But both in gait-condition two $(M=1.71, S E=.40, z=4.25, p<.001)$ and in gait-condition three $(M=1.85$, $S E=.40, z=4.58, p<.001)$ a significant increase in stride time was estimated.

\section{Velocity: Left Foot}

The velocity of the left foot was modeled best by including walking-direction $\left(\chi^{2}(1)=\right.$ $17.53, p<.001)$ and gait-condition $\left(\chi^{2}(2)=90.51, p<.001\right)$, but not diagnosis $\left(\chi^{2}(1)=2.56, p\right.$ 
$=.11)$. A model including an interaction term between the two independent variables improved the model fit significantly $\left(\chi^{2}(2)=8.33, p=.02\right)$, but in post hoc tests only the influence of the gaitconditions reached significance. Subjects moved their left foot significantly slower in gaitcondition two $(M=-.07, S E=.01, z=-7.20, p<.001)$ and gait-condition three $(M=-.04, S E=.01$, $z=-3.74, p<.001$, see also Fig. 7). The interaction effect between walking-direction and gait-condition, as well as the walking-direction as a main effect did not reach significance in post hoc tests.

\section{Velocity: Right Foot}

For the velocity of the right foot, inclusion of the gait-condition $\left(\chi^{2}(2)=203.80, p<.001\right)$ and the diagnosis $\left(\chi^{2}(1)=4.89, p=.03\right)$ had a significant influence on the fit of the model to the data. Including the walking-direction as a dependent variable did not improve the model fit significantly $\left(\chi^{2}(1)=3.47, p=.06\right)$. In post hoc tests we observed no significant influence of the diagnosis on the velocity of the right foot $(M=-.09, S E=.04, z=-2.28, p=.08)$. But similar to the velocity of the left foot, subjects moved their right foot significantly slower in gait-condition two $(M=-.09, S E=.01, z=-12.87, p<.001)$ and gait-condition three $(M=-.08, S E=.01, z=$ 11.78, $p<.001$; see also Fig. 7).

\section{Acceleration: Left Foot}

Results for the acceleration of the left foot show a similar pattern as the results for velocity for the same foot. Model fit was improved significantly by including walking-direction $\left(\chi^{2}(1)=\right.$ $37.01, p<.001)$ and gait-condition $\left(\chi^{2}(2)=132.14, p<.001\right)$, but not diagnosis $\left(\chi^{2}(1)=2.97, p\right.$ $=.08$ ). Again, a model including an interaction term between the two independent variables improved the model fit significantly $\left(\chi^{2}(2)=9, p=.01\right)$. In post hoc tests only the influence of the gait-conditions reached significance. Subjects accelerated their left foot significantly less in gaitcondition two $(M=-.04, S E=.01, z=-7.39, p<.001)$ and gait-condition three $(M=-.03, S E=.01$, $z=-4.86, p<.001)$. The interaction effect between walking-direction and gait-condition, as well as the walking-direction as a main effect did not reach significance in post hoc tests. 


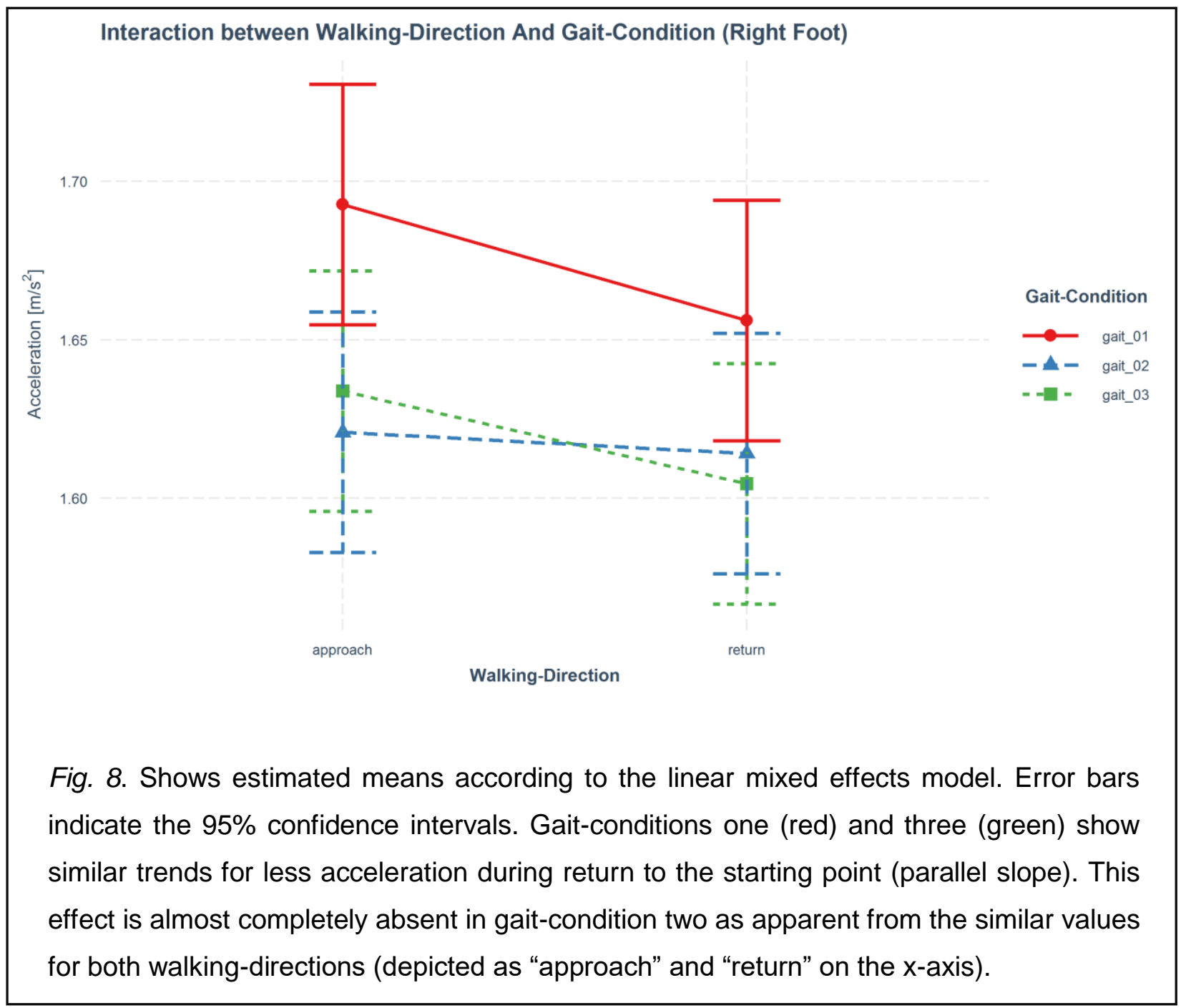

\section{Acceleration: Right Foot}

Model fit for the acceleration of the right foot was improved significantly by including walking-direction $\left(\chi^{2}(1)=51.72, p<.001\right)$ and gait-condition $\left(\chi^{2}(2)=254.58, p<.001\right)$, but not diagnosis $\left(\chi^{2}(1)=1.71, p=.19\right)$. A model including an interaction term between the two independent variables improved the model fit significantly $\left(\chi^{2}(2)=14.8, p<.001\right)$. Post hoc tests revealed that subjects accelerated their right foot significantly less when walking back towards the starting point $(M=-.04, S E=.01, z=-6.4, p<.001)$, as well as in gait-condition two $(M=-.07$, $S E=.01, z=-12.5, p<.001)$ and gait-condition three $(M=-.06, S E=.01, z=-10.2, p<.001)$. The interaction between walking-direction and gait-condition has a negative influence on the two 
main effects, leading to an attenuation when subjects walked towards the starting point in gaitcondition two $(M=.03, S E=.01, z=3.7, p<.01$; see Fig. 8).

\subsection{Results Experiment Two: Movement \& Mood}

The following dependent variables were analyzed for the cleaning-recordings:
a) velocity (of left hand and right hand)
b) acceleration (of left hand and right hand)

The following independent variables were tested for their effect on the respective dependent variable:
a) activity (mopping vs. sweeping)
b) mood (angry vs. happy)
c) diagnosis (ASD vs. TD)

In contrast to Experiment One, we found a significant influence of the diagnosis on all dependent variables. In addition, a three-way interaction was found between the dependent variables in case of all independent variables (see also Appendix B).

\section{Velocity: Right Hand}

The model fit for the velocity of the right hand was significantly improved by including $\operatorname{mood}\left(\chi^{2}(1)=47762.8, p<.001\right)$, activity $\left(\chi^{2}(1)=10851.4, p<.001\right)$, and diagnosis $\left(\chi^{2}(1)=\right.$ 15.6, $p<.001)$. A model including an interaction term between the three independent variables improved the model fit significantly $\left(\chi^{2}(4)=2324.1, p<.001\right)$. Post hoc tests revealed that subjects moved their right hand significantly faster during sweeping $(M=.1, S E=.002, z=40.54, p<.001)$ but significantly slower during the happy activities $(M=-.31, S E=.002, z=-133.61, p<.001)$. Subjects in the ASD group moved their right hand significantly slower than TD subjects $(M=-.34$, $S E=.06, z=-5.31, p<.001)$. Furthermore, the three-way interaction between the independent variables reached significance in post hoc tests $(M=-.21, S E=.006, z=-35.97, p<.001$; see Fig. 9). 


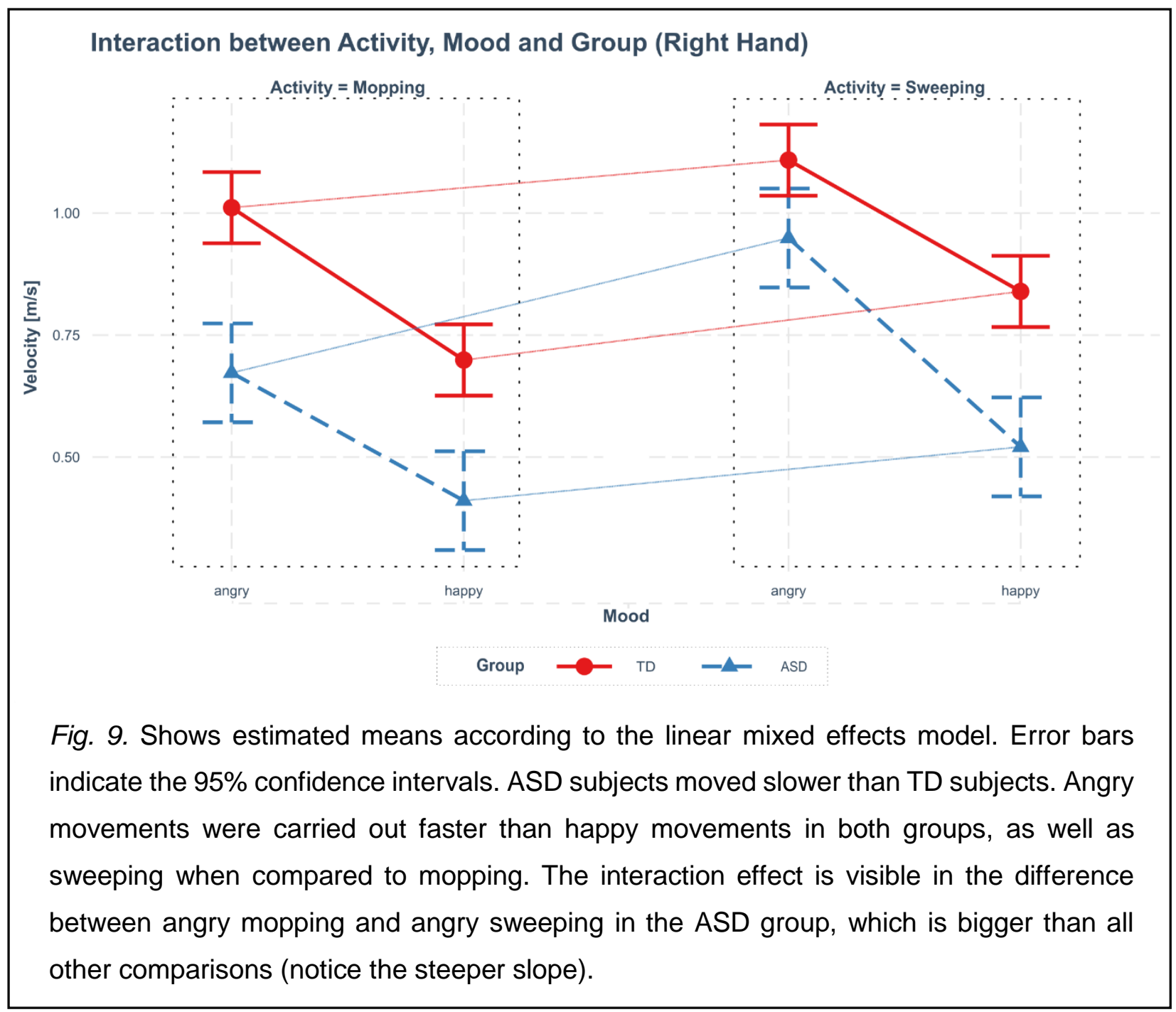

\section{Velocity: Left Hand}

The results for the velocity of the left hand show a very similar pattern to the right hand. The $\operatorname{mood}\left(\chi^{2}(1)=50207, p<.001\right)$, activity $\left(\chi^{2}(1)=8671, p<.001\right)$, as well as the diagnosis $\left(\chi^{2}\right.$ $(1)=14, p<.001)$ improved the model fit significantly. A model including an interaction term between the three independent variables improved the model fit significantly $\left(\chi^{2}(4)=1979, p\right.$ $<.001)$. Post hoc tests revealed that subjects moved their left hand significantly faster during sweeping $(M=.09, S E=.002, z=37.42, p<.001)$ but significantly slower during the happy activities $(M=-.30, S E=.002, z=-136.21, p<.001)$. Subjects in the ASD group moved their left hand significantly slower than TD subjects $(M=-.33, S E=.06, z=-5.05, p<.001)$. Again, the three-way interaction between the independent variables reached significance in post hoc tests $(M$ $=-.18, S E=.006, z=-32.61, p<.001)$. 


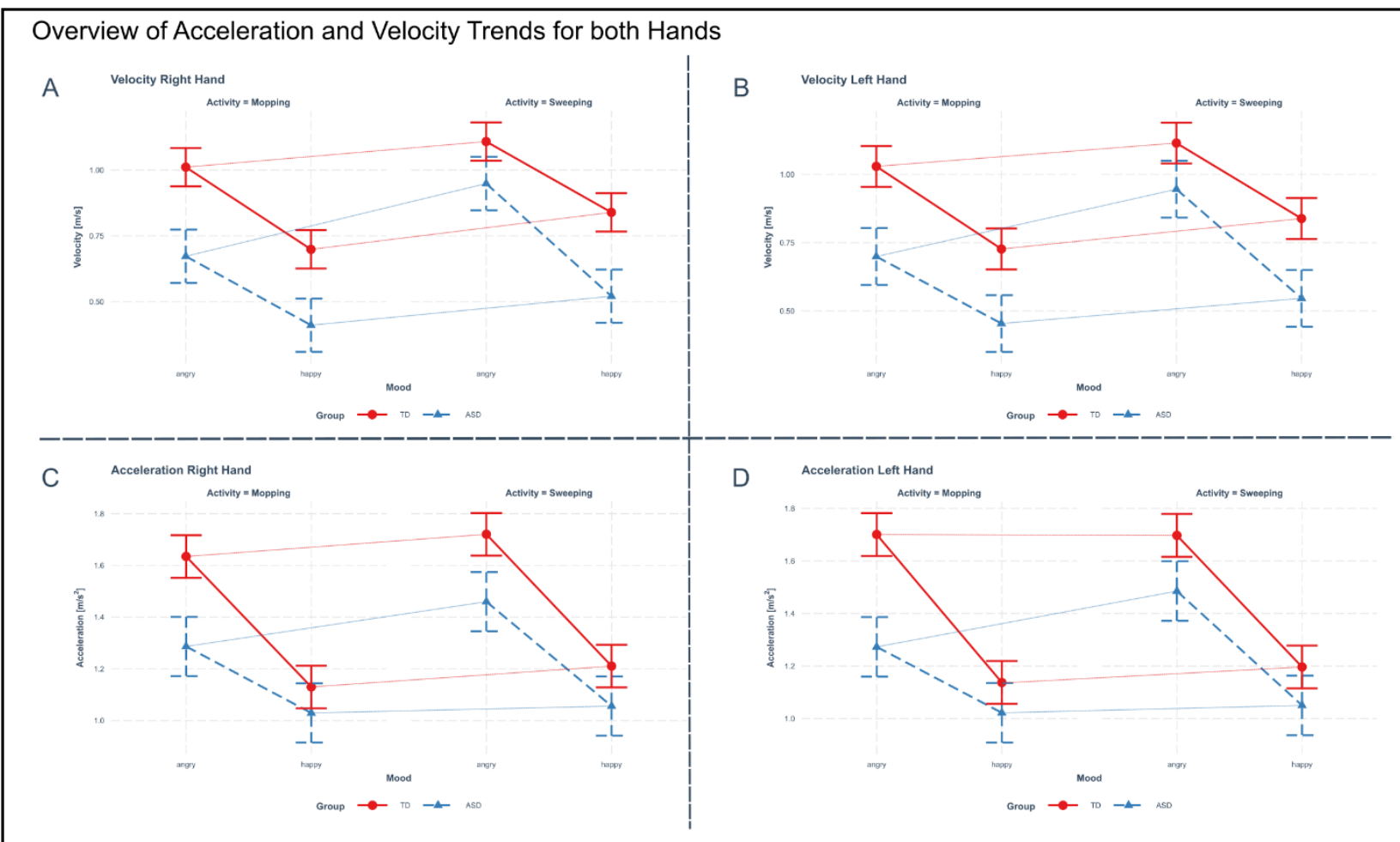

Fig. 10. Overview of left and right hand, as well as both velocity (A, B) and acceleration (C, D) as dependent variables. All plots show estimated means according to the linear mixed effects models. Error bars indicate the $95 \%$ confidence intervals. Overall trends are similar: mopping is carried out slower than sweeping, happy movements are slower than angry movements. ASD subjects move slower than TD subjects.

\section{Acceleration: Right Hand}

General trends for the acceleration of each hand appear similar to the velocity of the respective hand (see Fig. 10). The model fit for the acceleration of the right hand was improved significantly by including $\operatorname{mood}\left(\chi^{2}(1)=49635.72, p<.001\right)$, activity $\left(\chi^{2}(1)=2055.10, p<.001\right)$, and diagnosis $\left(\chi^{2}(1)=7.97, p<.01\right)$. A model including an interaction term between the three independent variables improved the model fit significantly $\left(\chi^{2}(4)=2242.76, p<.001\right)$. Post hoc tests revealed that subjects accelerated their right hand significantly more during sweeping $(M=.9$, $S E=.003, z=24.80, p<.001)$ and significantly less during the happy activities $(M=-.50, S E$ $=.003, z=-149.91, p<.001)$. Subjects in the ASD group accelerated their right hand significantly less than TD subjects $(M=-.34, S E=.07, z=-4.84, p<.001)$. The three-way interaction between mood, activity and diagnosis did reach significance $(M=-.14, S E=.01, z=-16.86, p<.001)$. 


\section{Acceleration: Left Hand}

$\operatorname{Mood}\left(\chi^{2}(1)=57379.46, p<.001\right)$, activity $\left(\chi^{2}(1)=975.28, p<.001\right)$, as well as the diagnosis $\left(\chi^{2}(1)=8.72, p<.01\right)$ improved the model fit significantly for the acceleration of the left hand. A model including an interaction term between the three independent variables improved the model fit further significantly $\left(\chi^{2}(4)=3606.99, p<.001\right)$. Again, post hoc tests revealed that subjects accelerated their left hand significantly less during the happy activities $(M=-.56, S E$ $=.003, z=-172.9, p<.001)$. Subjects in the ASD group accelerated their left hand significantly less than TD subjects $(M=-.43, S E=.07, z=-6, p<.001)$. The influence of the activity as a main effect did not reach significance in post hoc tests $(M=-.003, S E=.003, z=-1, p=.89)$. The threeway interaction between the independent variables reached significance $(M=-.24, S E=.01, z=$ $30.4, p<.001)$.

\section{Discussion}

We utilized motion capture technology to quantify whole-body movements of adult subjects with and without ASD. In Experiment One, focusing on spontaneous walking, we found no differences between the TD and the ASD group in any investigated parameter. In contrast to that, we found significant differences between TD and ASD in Experiment Two, focusing on mood-influenced everyday activities.

\subsection{Discussion Experiment One: Gait}

Our hypotheses concerning reduced walking speed $(H 1 a)$ and reduced stride length $(H 1 b)$ in ASD were not confirmed by our results. An effect on the ASD group via the gait-conditions was also falsified by our data (H2). Only the hypothesis concerning increased walking speed towards an object was confirmed $(H 3)$.

Our data show no reduction in acceleration or velocity when comparing ASD and TD walking data. Reduced walking speed was found in ASD by few studies (Ambrosini et al., 1998; Armitano et al., 2020; Morrison et al., 2018; Weiss et al., 2013), but several others reported no quantitative differences between ASD and TD (Biffi et al., 2018; Calhoun et al., 2011; Chester \& Calhoun, 2012; Hallett et al., 1993; Manicolo et al., 2019; Nayate et al., 2012; Rinehart, Tonge, Bradshaw, et al., 2006; Rinehart, Tonge, Iansek, et al., 2006; Vernazza-Martin et al., 2005). Our results corroborate the findings of the majority of studies on walking speed in ASD. 
Our results for stride length show no group differences (ASD vs. TD). Again, reduced stride/step length was found by few studies (Ambrosini et al., 1998; Nobile et al., 2011; VernazzaMartin et al., 2005; Vilensky et al., 1981; Weiss et al., 2013), however, a number of other studies found no differences (Biffi et al., 2018; Calhoun et al., 2011; Chester \& Calhoun, 2012; Manicolo et al., 2019; Nayate et al., 2012; Rinehart, Tonge, Bradshaw, et al., 2006; Rinehart, Tonge, Iansek, et al., 2006).

The hypothesized effect of the presence of a person in the field of view on the ASD participants was not found. However, our data suggest that the presence of a person had indeed an effect on the walking parameters of all participants. Our analysis shows that out of the independent variables under investigation, the gait-condition was of the most consistent influence on the different dependent variables. In comparison to gait-condition one, the second condition ("person present", cf. Fig. 2) was constantly found to be significantly different. This holds true for all investigated dependent variables: stride length, stride time, velocity, and acceleration. This effect is not restricted to either of the two groups (ASD or TD). In condition two, subjects were 1) walking slower, 2) taking smaller strides that 3) took more time. Walking towards another person may influence how we move, even if that person is not part of the current activity, but rather a bystander. Note, that the experimenter standing in the target area did not establish eye contact, but took notes while the participants were walking towards her. We can thus argue, that the mere presence of the experimenter may be influencing the walking parameters of the participants. Condition two shows another interesting feature, as opposed to both other conditions: while in condition one and three there is similar trend for less acceleration of the right foot while returning to the starting point, this effect is attenuated in condition two (see Fig. 8). In condition two, both directions of walking (approaching target area, returning to starting point) are relatively equal due to the interaction effect between walking-direction and gait-condition found in our analysis (cf. Fig. 8). One possible explanation could be the presence of the experimenter who remained in the target area and thus would be possibly observing the participants from behind their backs. This possibility of being observed from behind could cause a feeling of unease that could in turn cause the participants to walk relatively faster. It should be noted however that this effect was only observed in one out of four variables of interest.

Generally, the biggest factor to restrict the interpretation of these results is the possible influence of an order effect, because the three gait-conditions were carried out in the same 
sequence by all participants. This was mandatory to maintain the cover story of calibrating the sensors by walking through the room (cf. Procedure Experiment One). It would be interesting to replicate these findings in a randomized design that would cancel out influences of an order effect.

No significant group differences were observed between ASD and TD in any investigated parameter of the gait recordings. A possible explanation is the profile of our ASD group. The participants in our study were all adults and can be placed in the realm of high functioning ASD. This is relevant for two reasons. Firstly, it is possible that developmental delays in motor abilities are compensated for with increasing age: in their study on gait variability in children with ASD, Manicolo et al. showed an age-dependent decrease, indicating a convergence towards gait patterns of TD children (Manicolo et al., 2019). Corroborating results were reported in a study on postural control that showed an age-dependent decrease in developmental delay in autistic subjects aged 5 - 52 (Minshew et al., 2004). Secondly, there is evidence suggesting that motor impairments are correlated to the degree of functioning (Cook et al., 2013; Minshew et al., 2004). Our data support both these findings. More studies with adult participants are needed to clarify the relation between motor impairments and age, as well as level of functioning.

\subsection{Discussion Experiment Two: Movement \& Mood}

To the best of our knowledge, this is the first study to investigate mood-influenced wholebody movement parameters in adult subjects with ASD. Our hypothesis concerning reduced velocity and acceleration of body movements in ASD was confirmed (H4): autistic subjects moved significantly slower than TD subjects when performing mood-influenced everyday activities. Together with the results from Experiment One that showed no group differences in neutral walking movements, the results of Experiment Two suggest that general motor skills are intact in adult HFA subjects, while mood-influenced body movements are measurable different. This suggests that the nonverbal signals (containing information about mood) produced by our subjects vary substantially between groups and that this difference is not due to an impairment in the motor system but rather a higher order cognitive system related to nonverbal behavior like MENT.

Angry movements were performed faster than happy movements by both TD and ASD participants. This is in line with previous research showing movements expressing anger were stronger and faster than movements expressing happiness (Roether et al., 2009; Sawada et al., 2003). 
The question of how these differences of velocity in the production of nonverbal bodily signals between groups will affect the perception thereof is perhaps the most interesting question arising from the current results. Previous research showed that the speed of body movements is the most prominent kinematic feature ascribed to movements produced under different emotional conditions (Barliya et al., 2013; Paterson et al., 2001; Sawada et al., 2003). If presented to TD subjects, the body movements of the ASD subjects will therefore most likely be perceived differently than those of the TD subjects. This seems plausible because TD persons are tuned to recognize movements that are similar to those they produce themselves (Casile \& Giese, 2006). Based on the literature, we would expect that ASD movements will be less well recognized when perceived by TD subjects and ASD subjects alike. At least for facial expressions, studies show this effect: facial expressions produced by autistic subjects are less well recognized when viewed by TD subjects (Brewer et al., 2016; Grossard et al., 2020; Macdonald et al., 1989; Volker et al., 2009), and notably also when viewed by other ASD subjects (Brewer et al., 2016). The findings by Brewer and colleagues indicate that ASD subjects do not share a common way of producing nonverbal signals that would be easier to interpret by other ASD subjects. Edey et al. found corroborating results in a very different approach when they let participants with and without ASD produce simple shape-based animations to portray mental states. Subsequently, TD participants were significantly more successful in recognizing the portrayed mental states in the animations produced by TD individuals, but the ASD participants did not show this "same group advantage" (Edey et al., 2016). A recent study by Georgescu et al. supports these findings by showing no increase in interpersonal synchrony between two ASD interaction partners, when compared to mixed (ASD + TD) or typical (TD + TD) dyads (Georgescu et al., 2020).

The finding of overall higher velocity and acceleration in TD participants in our data on the one hand and better recognition rates of nonverbal signals produced by TD subjects in the literature on the other hand fit in with previous research showing a direct association of intensity and recognition accuracy of facial expressions (Hess et al., 1997). Another study showed that highintensity facial expressions of anger and happiness were correctly identified more often than lowintensity expressions (Zupan, 2015). This supports the notion that the current whole-body movement recordings will be perceived differently depending on the group (ASD vs. TD).

Although there is a significant within-group velocity difference between moods (e.g. happy vs. angry mopping in ASD), there is also a significant between-group difference (e.g. happy 
mopping in ASD vs. happy mopping in TD). Interesting questions arise from this constellation: on the level of perception, is it similarly difficult to distinguish the individual within-group differences, e.g. is happy vs. angry mopping in ASD similarly difficult to discern compared to happy vs. angry mopping in TD? To date, no studies have investigated this type of question for whole-body movements. Based on the results of studies in other nonverbal channels we would expect that the within-group differences of the ASD participants will be less well recognized. For example, Grossard et al. recently investigated facial expressions in children with and without ASD and found that children with ASD produced facial expressions that were more ambiguous than those of the TD children (Grossard et al., 2020).

Our results on the level of production of nonverbal signals in ASD add to the existing results on the level of perception. While participants with ASD in the study of Marx (2018) had no impairments in recognizing a given activity (e.g. mopping), they showed more uncertainty in recognizing the underlying mood (e.g. happy) (Marx, 2018). By additionally transferring the imaging results from Geiger et al. (2019) to the behavioral level we can arrive at the conclusion that the current results corroborate the hypothesis that MNS-associated tasks are less impaired in ASD than MENT-associated ones. While Marx (2018) showed this effect on the level of perception of bodily signals in ASD, our results show a similar effect on the level of production of nonverbal signals. General motor skills like walking are not impaired in our ASD sample, while body movements related to the production of nonverbal signals are significantly different. It would be interesting to investigate the neural underpinnings of this kind of motor behavior in ASD, e.g. with existing approaches utilizing mobile electroencephalography (see e.g. Gramann et al., 2014).

In sum, the results of the current study show that aberrant motor skills in adult HFA subjects were not evident in general motor tasks like walking, but in mood-influenced everyday activities. This quantitative difference of movements underlying nonverbal signals sheds new light on the difficulties of interpersonal communication in ASD. Experiments are already planned, that use the recorded movements of both ASD and TD participants to investigate how they will be perceived by a new cohort of subjects with and without ASD. 


\section{Acknowledgements}

I would like to thank my supervisor Professor Dr. Dr. Kai Vogeley for giving me the opportunity to work on such a highly interesting and challenging project. A big thank you to Carola Bloch for the help in preparation and realization of the motion capture recordings. Thank you to Shivakumar Viswanathan for suggesting interesting analysis approaches. Thank you to Mathis Jording and David Vogel for stimulating discussions. 


\section{References}

Alcalá-López, D., Vogeley, K., Binkofski, F., \& Bzdok, D. (2018). Building blocks of social cognition: Mirror, mentalize, share? Cortex. https://doi.org/10.1016/j.cortex.2018.05.006

Ambrosini, D., Courchesne, E., \& Kaufman, K. R. (1998). Motion analysis of patients with infantile autism. Gait and Posture, 7(2).

https://mayoclinic.pure.elsevier.com/en/publications/motion-analysis-of-patients-withinfantile-autism

American Psychiatric Association. (2013). Diagnostic and Statistical Manual of Mental Disorders (Fifth Edition). American Psychiatric Publishing.

App, B., McIntosh, D. N., Reed, C. L., \& Hertenstein, M. J. (2011). Nonverbal channel use in communication of emotion: How may depend on why. Emotion (Washington, D.C.), 11(3), 603-617. https://doi.org/10/d3d5c9

Argyle, M. (1988). Bodily Communication. Routledge.

Argyle, M., Salter, V., Nicholson, H., Williams, M., \& Burgess, P. (1970). The Communication of Inferior and Superior Attitudes by Verbal and Non-verbal Signals. British Journal of Social and Clinical Psychology, 9(3), 222-231. https://doi.org/10.1111/j.20448260.1970.tb00668.x

Armitano, C. N., Bennett, H. J., Haegele, J. A., \& Morrison, S. (2020). Assessment of the gaitrelated acceleration patterns in adults with autism spectrum disorder. Gait \& Posture, 75, 155-162. https://doi.org/10/ggdc2f

Asperger, H. (1944). Die „Autistischen Psychopathen” im Kindesalter. Archiv für Psychiatrie und Nervenkrankheiten, 117(1), 76-136. https://doi.org/10.1007/BF01837709 
Aviezer, H., Trope, Y., \& Todorov, A. (2012). Body cues, not facial expressions, discriminate between intense positive and negative emotions. Science (New York, N.Y.), 338(6111), 1225-1229. https://doi.org/10.1126/science.1224313

Barliya, A., Omlor, L., Giese, M. A., Berthoz, A., \& Flash, T. (2013). Expression of emotion in the kinematics of locomotion. Experimental Brain Research, 225(2), 159-176. https://doi.org/10.1007/s00221-012-3357-4

Baron-Cohen, S. (2001). Theory of mind in normal development and autism. 23.

Baron-Cohen, S., Leslie, A. M., \& Frith, U. (1985). Does the autistic child have a "theory of mind" ? Cognition, 21(1), 37-46. https://doi.org/10.1016/0010-0277(85)90022-8

Bates, D., Mächler, M., Bolker, B., \& Walker, S. (2015). Fitting Linear Mixed-Effects Models Using lme4. Journal of Statistical Software, 67(1), 1-48. https://doi.org/10.18637/jss.v067.i01

Biffi, E., Costantini, C., Ceccarelli, S. B., Cesareo, A., Marzocchi, G. M., Nobile, M., Molteni, M., \& Crippa, A. (2018). Gait Pattern and Motor Performance During Discrete Gait Perturbation in Children With Autism Spectrum Disorders. Frontiers in Psychology, 9, 2530. https://doi.org/10.3389/fpsyg.2018.02530

Blake, R., \& Shiffrar, M. (2007). Perception of human motion. Annual Review of Psychology, 58, 47-73. https://doi.org/10/fr7p9h

Bottema-Beutel, K., Kim, S. Y., \& Crowley, S. (2018). A systematic review and meta-regression analysis of social functioning correlates in autism and typical development. Autism Research: Official Journal of the International Society for Autism Research. https://doi.org/10.1002/aur.2055 
Brewer, R., Biotti, F., Catmur, C., Press, C., Happé, F., Cook, R., \& Bird, G. (2016). Can Neurotypical Individuals Read Autistic Facial Expressions? Atypical Production of Emotional Facial Expressions in Autism Spectrum Disorders. Autism Research: Official Journal of the International Society for Autism Research, 9(2), 262-271. https://doi.org/10/f8c5x4

Burgoon, J. K., Guerrero, L. K., \& Manusov, V. (2011). Nonverbal signals. In M. L. Knapp \& J. A. Daly (Eds.), The SAGE Handbook of Interpersonal Communication (4th edition, pp. 239-283). SAGE Publications, Inc.

Calhoun, M., Longworth, M., \& Chester, V. L. (2011). Gait patterns in children with autism. Clinical Biomechanics (Bristol, Avon), 26(2), 200-206. https://doi.org/10.1016/j.clinbiomech.2010.09.013

Caramazza, A., Anzellotti, S., Strnad, L., \& Lingnau, A. (2014). Embodied Cognition and Mirror Neurons: A Critical Assessment. Annual Review of Neuroscience, 37(1), 1-15. https://doi.org/10/gffjnz

Casile, A., \& Giese, M. A. (2006). Nonvisual Motor Training Influences Biological Motion Perception. Current Biology, 16(1), 69-74. https://doi.org/10/b4gn57

Caspers, S., Zilles, K., Laird, A. R., \& Eickhoff, S. B. (2010). ALE meta-analysis of action observation and imitation in the human brain. NeuroImage, 50(3), 1148-1167. https://doi.org/10.1016/j.neuroimage.2009.12.112

Chaste, P., \& Leboyer, M. (2012). Autism risk factors: Genes, environment, and geneenvironment interactions. Dialogues in Clinical Neuroscience, 14(3), 281-292.

Chester, V. L., \& Calhoun, M. (2012). Gait symmetry in children with autism. Autism Research and Treatment, 2012, 576478. https://doi.org/10/gb8mbg 
Cook, J. L., Blakemore, S.-J., \& Press, C. (2013). Atypical basic movement kinematics in autism spectrum conditions. Brain: A Journal of Neurology, 136(Pt 9), 2816-2824. https://doi.org/10.1093/brain/awt208

Cross, E. S., Hamilton, A. F. de C., \& Grafton, S. T. (2006). Building a motor simulation de novo: Observation of dance by dancers. NeuroImage, 31(3), 1257-1267. https://doi.org/10/c865c5

de Lange, F. P., Spronk, M., Willems, R. M., Toni, I., \& Bekkering, H. (2008). Complementary Systems for Understanding Action Intentions. Current Biology, 18(6), 454-457. https://doi.org/10.1016/j.cub.2008.02.057

di Pellegrino, G., Fadiga, L., Fogassi, L., Gallese, V., \& Rizzolatti, G. (1992). Understanding motor events: A neurophysiological study. Experimental Brain Research, 91(1), 176-180. https://doi.org/10/btr2pk

Diamond, A. (2013). Executive Functions. Annual Review of Psychology, 64(1), 135-168. https://doi.org/10/b2m2

Dinstein, I., Thomas, C., Behrmann, M., \& Heeger, D. J. (2008). A mirror up to nature. Current Biology, 18(1), R13-R18. https://doi.org/10.1016/j.cub.2007.11.004

Donnellan, A. M., Hill, D. A., \& Leary, M. R. (2013). Rethinking autism: Implications of sensory and movement differences for understanding and support. Frontiers in Integrative Neuroscience, 6. https://doi.org/10.3389/fnint.2012.00124

Edey, R., Cook, J., Brewer, R., Johnson, M. H., Bird, G., \& Press, C. (2016). Interaction takes two: Typical adults exhibit mind-blindness towards those with autism spectrum disorder. Journal of Abnormal Psychology, 125(7), 879-885. https://doi.org/10.1037/abn0000199 
Espy, K. A. (2004). Using developmental, cognitive, and neuroscience approaches to understand executive control in young children. Developmental Neuropsychology, 26(1), 379-384. https://doi.org/10/brjc75

Fishman, I., Keown, C. L., Lincoln, A. J., Pineda, J. A., \& Müller, R.-A. (2014). Atypical cross talk between mentalizing and mirror neuron networks in autism spectrum disorder. JAMA Psychiatry, 71(7), 751-760. https://doi.org/10.1001/jamapsychiatry.2014.83

Fombonne, E. (2009). Epidemiology of pervasive developmental disorders. Pediatric Research, 65(6), 591-598. https://doi.org/10/fppgjn

Fournier, K. A., Hass, C. J., Naik, S. K., Lodha, N., \& Cauraugh, J. H. (2010). Motor Coordination in Autism Spectrum Disorders: A Synthesis and Meta-Analysis. Journal of Autism and Developmental Disorders, 40(10), 1227-1240. https://doi.org/10.1007/s10803-010-0981-3

Frith, C. D., \& Frith, U. (2012). Mechanisms of social cognition. Annual Review of Psychology, 63, 287-313. https://doi.org/10.1146/annurev-psych-120710-100449

Frith, U., Morton, J., \& Leslie, A. M. (1991). The cognitive basis of a biological disorder: Autism. Trends in Neurosciences, 14(10), 433-438. https://doi.org/10.1016/01662236(91)90041-R

Frith, Uta. (1989). Autism: Explaining the Enigma ('1). Wiley-Blackwell.

Gallese, V., Fadiga, L., Fogassi, L., \& Rizzolatti, G. (1996). Action recognition in the premotor cortex. Brain: A Journal of Neurology, 119 ( Pt 2), 593-609.

Geiger, A., Bente, G., Lammers, S., Tepest, R., Roth, D., Bzdok, D., \& Vogeley, K. (2019). Distinct functional roles of the mirror neuron system and the mentalizing system. NeuroImage, 202, 116102. https://doi.org/10.1016/j.neuroimage.2019.116102 
Georgescu, A. L., Koeroglu, S., Hamilton, A. F. de C., Vogeley, K., Falter-Wagner, C. M., \& Tschacher, W. (2020). Reduced nonverbal interpersonal synchrony in autism spectrum disorder independent of partner diagnosis: A motion energy study. Molecular Autism, 11(1), 11. https://doi.org/10/ggj642

Gramann, K., Ferris, D. P., Gwin, J., \& Makeig, S. (2014). Imaging natural cognition in action. International Journal of Psychophysiology: Official Journal of the International Organization of Psychophysiology, 91(1), 22-29. https://doi.org/10/f5tsdz

Grossard, C., Dapogny, A., Cohen, D., Bernheim, S., Juillet, E., Hamel, F., Hun, S., Bourgeois, J., Pellerin, H., Serret, S., Bailly, K., \& Chaby, L. (2020). Children with autism spectrum disorder produce more ambiguous and less socially meaningful facial expressions: An experimental study using random forest classifiers. Molecular Autism, 11, 5. https://doi.org/10/ggk3n4

Hallett, M., Lebiedowska, M. K., Thomas, S. L., Stanhope, S. J., Denckla, M. B., \& Rumsey, J. (1993). Locomotion of autistic adults. Archives of Neurology, 50(12), 1304-1308. https://doi.org/10.1001/archneur.1993.00540120019007

Hamilton, A. F. de C. (2008). Emulation and Mimicry for Social Interaction: A Theoretical Approach to Imitation in Autism. Quarterly Journal of Experimental Psychology, 61(1), 101-115. https://doi.org/10.1080/17470210701508798

Hamilton, A. F. de C. (2013). Reflecting on the mirror neuron system in autism: A systematic review of current theories. Developmental Cognitive Neuroscience, 3, 91-105. https://doi.org/10.1016/j.dcn.2012.09.008 
Happé, F., \& Frith, U. (2006). The weak coherence account: Detail-focused cognitive style in autism spectrum disorders. Journal of Autism and Developmental Disorders, 36(1), 5-25. https://doi.org/10/dp3b39

Hess, U., Blairy, S., \& Kleck, R. E. (1997). The Intensity of Emotional Facial Expressions and Decoding Accuracy. Journal of Nonverbal Behavior, 21(4), 241-257. https://doi.org/10/bwksx2

Hickok, G. (2009). Eight Problems for the Mirror Neuron Theory of Action Understanding in Monkeys and Humans. Journal of Cognitive Neuroscience, 21(7), 1229-1243. https://doi.org/10.1162/jocn.2009.21189

Hickok, G. (2014). The Myth of Mirror Neurons: The Real Neuroscience of Communication and Cognition (1st ed.). W. W. Norton \& Company.

Hill, E. L. (2004). Evaluating the theory of executive dysfunction in autism. Developmental Review, 24(2), 189-233. https://doi.org/10/c2brr2

Hothorn, T., Bretz, F., \& Westfall, P. (2008). Simultaneous inference in general parametric models. Biometrical Journal, 50(3), 346-363. https://doi.org/10.1002/bimj.200810425

Iacoboni, M., \& Dapretto, M. (2006). The mirror neuron system and the consequences of its dysfunction. Nature Reviews Neuroscience, 7(12), 942-951. https://doi.org/10.1038/nrn2024

Johnson, B. P., Phillips, J. G., Papadopoulos, N., Fielding, J., Tonge, B., \& Rinehart, N. J. (2013). Understanding macrographia in children with autism spectrum disorders. Research in Developmental Disabilities, 34(9), 2917-2926. https://doi.org/10/f45vf7

Kanner, L. (1943). Autistic disturbances of affective contact. Nervous Child, 2, 217-250. 
Kilner, J., Hamilton, A. F. de C., \& Blakemore, S.-J. (2007). Interference effect of observed human movement on action is due to velocity profile of biological motion. Social Neuroscience, 2(3-4), 158-166. https://doi.org/10.1080/17470910701428190

Kilner, J., Paulignan, Y., \& Blakemore, S. J. (2003). An interference effect of observed biological movement on action. Current Biology: CB, 13(6), 522-525. https://doi.org/10/bnw2ns

Lammers, S. (2017). Production and Perception of Whole-Body Movements to Probe the Social Brain [B.Sc. Thesis, University of Cologne]. https://doi.org/10.31237/osf.io/swucv. https://doi.org/10.31237/osf.io/swucv

Lammers, S., Bente, G., Tepest, R., Jording, M., Roth, D., \& Vogeley, K. (2019). Introducing ACASS: An Annotated Character Animation Stimulus Set for Controlled (e)Motion Perception Studies. Frontiers in Robotics and AI, 6. https://doi.org/10.3389/frobt.2019.00094

Leary, M. R., \& Hill, D. A. (1996). Moving on: Autism and movement disturbance. Mental Retardation, 34(1), 39-53.

Lehrl, S., Triebig, G., \& Fischer, B. (1995). Multiple choice vocabulary test MWT as a valid and short test to estimate premorbid intelligence. Acta Neurologica Scandinavica, 91(5), 335345. https://doi.org/10/cjj9ch

Libero, L. E., Maximo, J. O., Deshpande, H. D., Klinger, L. G., Klinger, M. R., \& Kana, R. K. (2014). The role of mirroring and mentalizing networks in mediating action intentions in autism. Molecular Autism, 5(1), 50. https://doi.org/10.1186/2040-2392-5-50

Macdonald, H., Rutter, M., Howlin, P., Rios, P., Le Conteur, A., Evered, C., \& Folstein, S. (1989). Recognition and expression of emotional cues by autistic and normal adults. 
Journal of Child Psychology and Psychiatry, and Allied Disciplines, 30(6), 865-877. https://doi.org/10/b5n9hg

Manicolo, O., Brotzmann, M., Hagmann-von Arx, P., Grob, A., \& Weber, P. (2019). Gait in children with infantile/atypical autism: Age-dependent decrease in gait variability and associations with motor skills. European Journal of Paediatric Neurology: EJPN: Official Journal of the European Paediatric Neurology Society, 23(1), 117-125. https://doi.org/10.1016/j.ejpn.2018.09.011

Marx, M. (2018). Mirroring and Mentalizin in Autism-Detection of Different Types of Movements and Emotions in Autism Spectrum Disorder [B.Sc. Thesis]. University of Cologne.

Meltzoff, A. N., \& Moore, M. K. (1977). Imitation of facial and manual gestures by human neonates. Science (New York, N.Y.), 198(4312), 74-78. https://doi.org/10/c6jcb9

Miller, E. K., \& Cohen, J. D. (2001). An integrative theory of prefrontal cortex function. Annual Review of Neuroscience, 24, 167-202. https://doi.org/10.1146/annurev.neuro.24.1.167

Minshew, N. J., Sung, K., Jones, B. L., \& Furman, J. M. (2004). Underdevelopment of the postural control system in autism. Neurology, 63(11), 2056-2061. https://doi.org/10/ggfhxz

Molenberghs, P., Cunnington, R., \& Mattingley, J. B. (2012). Brain regions with mirror properties: A meta-analysis of 125 human fMRI studies. Neuroscience \& Biobehavioral Reviews, 36(1), 341-349. https://doi.org/10/b7q369

Morrison, S., Armitano, C. N., Raffaele, C. T., Deutsch, S. I., Neumann, S. A., Caracci, H., \& Urbano, M. R. (2018). Neuromotor and cognitive responses of adults with autism 
spectrum disorder compared to neurotypical adults. Experimental Brain Research, 236(8), 2321-2332. https://doi.org/10/gdwx9n

Nagy, E. (2006). From imitation to conversation: The first dialogues with human neonates. Infant and Child Development, 15(3), 223-232. https://doi.org/10/bcxg5q

Nayate, A., Tonge, B. J., Bradshaw, J. L., McGinley, J. L., Iansek, R., \& Rinehart, N. J. (2012). Differentiation of high-functioning autism and Asperger's disorder based on neuromotor behaviour. Journal of Autism and Developmental Disorders, 42(5), 707-717. https://doi.org/10/d4d55z

Newschaffer, C. J., Croen, L. A., Daniels, J., Giarelli, E., Grether, J. K., Levy, S. E., Mandell, D. S., Miller, L. A., Pinto-Martin, J., Reaven, J., Reynolds, A. M., Rice, C. E., Schendel, D., \& Windham, G. C. (2007). The Epidemiology of Autism Spectrum Disorders. Annual Review of Public Health, 28(1), 235-258. https://doi.org/10/fjkxsj

Nobile, M., Perego, P., Piccinini, L., Mani, E., Rossi, A., Bellina, M., \& Molteni, M. (2011). Further evidence of complex motor dysfunction in drug naive children with autism using automatic motion analysis of gait. Autism: The International Journal of Research and Practice, 15(3), 263-283. https://doi.org/10.1177/1362361309356929

Oberman, L. M., Hubbard, E. M., McCleery, J. P., Altschuler, E. L., Ramachandran, V. S., \& Pineda, J. A. (2005). EEG evidence for mirror neuron dysfunction in autism spectrum disorders. Brain Research. Cognitive Brain Research, 24(2), 190-198. https://doi.org/10.1016/j.cogbrainres.2005.01.014

Parma, V., \& de Marchena, A. B. (2015). Motor signatures in autism spectrum disorder: The importance of variability. Journal of Neurophysiology, 115(3), 1081-1084. https://doi.org/10/f3vj3k 
Paterson, H., Pollick, F., \& Sanford, A. (2001). The role of velocity in affect discrimination. Proceedings of the 23rd Annual Conference of the Cognitive Science Society, 756-761.

Pinheiro, J. C., \& Bates, D. (2009). Mixed-Effects Models in S and S-PLUS (2000th ed.). Springer.

Pirker, W., \& Katzenschlager, R. (2017). Gait disorders in adults and the elderly. Wiener Klinische Wochenschrift, 129(3), 81-95. https://doi.org/10.1007/s00508-016-1096-4

Poppe, R., Van Der Zee, S., Heylen, D. K. J., \& Taylor, P. J. (2014). AMAB: Automated measurement and analysis of body motion. Behavior Research Methods, 46(3), 625-633. https://doi.org/10.3758/s13428-013-0398-y

R Core Team. (2019). R: A language and environment for statistical computing. https://www.Rproject.org/

Rinehart, N. J., Tonge, B. J., Bradshaw, J. L., Iansek, R., Enticott, P. G., \& McGinley, J. (2006). Gait function in high-functioning autism and Asperger's disorder: Evidence for basalganglia and cerebellar involvement? European Child \& Adolescent Psychiatry, 15(5), 256-264. https://doi.org/10/crhfb4

Rinehart, N. J., Tonge, B. J., Iansek, R., McGinley, J., Brereton, A. V., Enticott, P. G., \& Bradshaw, J. L. (2006). Gait function in newly diagnosed children with autism: Cerebellar and basal ganglia related motor disorder. Developmental Medicine and Child Neurology, 48(10), 819-824. https://doi.org/10/fhc74z

Roether, C. L., Omlor, L., Christensen, A., \& Giese, M. A. (2009). Critical features for the perception of emotion from gait. Journal of Vision, 9(6), 15.1-32. https://doi.org/10.1167/9.6.15 
RStudio Team. (2018). RStudio: Integrated development environment for $R$. http://www.rstudio.com/

Satzger, W., Fessmann, H., \& Engel, R. R. (2002). Liefern HAWIE-R, WST und MWT-B vergleichbare IQ-Werte? Zeitschrift Für Differentielle Und Diagnostische Psychologie. https://doi.org/10/ftjj36

Sawada, M., Suda, K., \& Ishii, M. (2003). Expression of emotions in dance: Relation between arm movement characteristics and emotion. Perceptual and Motor Skills, 97(3 Pt 1), 697708. https://doi.org/10.2466/pms.2003.97.3.697

Spunt, R. P., Falk, E. B., \& Lieberman, M. D. (2010). Dissociable Neural Systems Support Retrieval of How and Why Action Knowledge. Psychological Science, 21(11), 15931598. https://doi.org/10.1177/0956797610386618

Spunt, R. P., \& Lieberman, M. D. (2012a). An integrative model of the neural systems supporting the comprehension of observed emotional behavior. NeuroImage, 59(3), 3050-3059. https://doi.org/10.1016/j.neuroimage.2011.10.005

Spunt, R. P., \& Lieberman, M. D. (2012b). Dissociating Modality-Specific and Supramodal Neural Systems for Action Understanding. Journal of Neuroscience, 32(10), 3575-3583. https://doi.org/10.1523/JNEUROSCI.5715-11.2012

Spunt, R. P., Satpute, A. B., \& Lieberman, M. D. (2011). Identifying the what, why, and how of an observed action: An fMRI study of mentalizing and mechanizing during action observation. Journal of Cognitive Neuroscience, 23(1), 63-74. https://doi.org/10.1162/jocn.2010.21446

Stoit, A. M. B., van Schie, H. T., Slaats-Willemse, D. I. E., \& Buitelaar, J. K. (2013). Grasping Motor Impairments in Autism: Not Action Planning but Movement Execution is 
Deficient. Journal of Autism and Developmental Disorders, 43(12), 2793-2806. https://doi.org/10/f5g7xx

Teitelbaum, P., Teitelbaum, O., Nye, J., Fryman, J., \& Maurer, R. G. (1998). Movement analysis in infancy may be useful for early diagnosis of autism. Proceedings of the National Academy of Sciences of the United States of America, 95(23), 13982-13987. https://doi.org/10.1073/pnas.95.23.13982

Troje, N. (2013). What Is Biological Motion? Definition, Stimuli, and Paradigms. In: Rutherford, M. D. and Kuhlmeier, V. A. (Eds.) Social Perception: Detection and Interpretation of Animacy, Agency, and Intention. MIT Press., 13-36. https://doi.org/10.7551/mitpress/9780262019279.003.0002

Velikonja, T., Fett, A.-K., \& Velthorst, E. (2019). Patterns of Nonsocial and Social Cognitive Functioning in Adults With Autism Spectrum Disorder: A Systematic Review and Metaanalysis. JAMA Psychiatry. https://doi.org/10.1001/jamapsychiatry.2018.3645

Vernazza-Martin, S., Martin, N., Vernazza, A., Lepellec-Muller, A., Rufo, M., Massion, J., \& Assaiante, C. (2005). Goal directed locomotion and balance control in autistic children. Journal of Autism and Developmental Disorders, 35(1), 91-102. https://doi.org/10/fgzh9v

Vilensky, J. A., Damasio, A. R., \& Maurer, R. G. (1981). Gait disturbances in patients with autistic behavior: A preliminary study. Archives of Neurology, 38(10), 646-649. https://doi.org/10.1001/archneur.1981.00510100074013

Vogeley, K. (2017). Two social brains: Neural mechanisms of intersubjectivity. Phil. Trans. R. Soc. B, 372(1727), 20160245. https://doi.org/10.1098/rstb.2016.0245 
Volker, M. A., Lopata, C., Smith, D. A., \& Thomeer, M. L. (2009). Facial Encoding of Children with High-Functioning Autism Spectrum Disorders. Focus on Autism and Other Developmental Disabilities, 24(4), 195-204. https://doi.org/10/dcvs8x

Wallbott, H. G. (1998). Bodily expression of emotion. European Journal of Social Psychology, 28(6), 879-896. https://doi.org/10/b6tn2w

Weiss, M. J., Moran, M. F., Parker, M. E., \& Foley, J. T. (2013). Gait analysis of teenagers and young adults diagnosed with autism and severe verbal communication disorders. Frontiers in Integrative Neuroscience, 7, 33. https://doi.org/10.3389/fnint.2013.00033

Zupan, B. (2015). Recognition of High and Low Intensity Facial and Vocal Expressions of Emotion by Children and Adults. Journal of Social Sciences and Humanities, 1(4), 332344. 


\section{Appendix}

\section{Appendix A: Source Code}

Below are all core functions of the preprocessing procedures that were developed in course of this project.

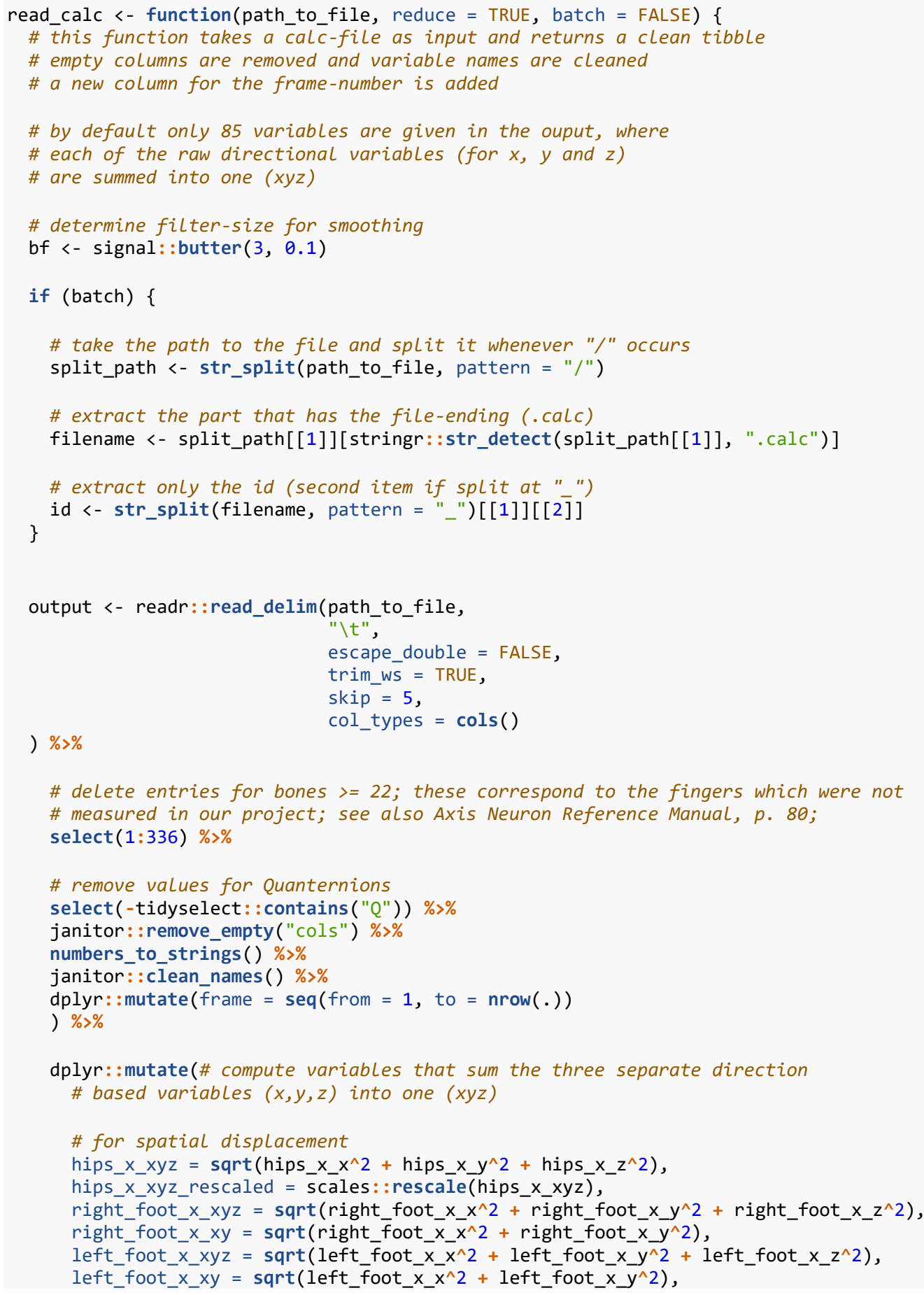


right_hand_x_xyz $=\operatorname{sqrt}\left(\right.$ right_hand_x_ $x^{\wedge} 2+$ right_hand_x_y^ $2+$ right_hand_x_z^ 2$)$, left_hand_x_xyz $=\operatorname{sqrt}\left(\right.$ left_hand_x_$x^{\wedge} 2+$ left_hand_x_y^$\overline{2}+$ left_hand_x_z $\left.z^{\wedge} 2\right)$,

\# for acceleration

hips_a_xyz $=\operatorname{sqrt}($ hips_a_x^2 + hips_a_y^2 + hips_a_z^2),

right_upleg_a_xyz = sqrt (right_upleg_z_t^2 + right_upleg_a_y^2 + right_upleg_a_z^2),

right_leg_a_xyz $=\operatorname{sqrt}\left(r i g h t \_l e g \_a \_x^{\wedge} 2+r i g h t \_l e g \_a \_y^{\wedge} 2+r i g h t \_l e g \_a \_z^{\wedge} 2\right)$,

right_foot_a_xyz = sqrt (right_foot_a_x^2 + right_foot_a_y^2 + right_foot_a_z^2),

left_upleg_a_xyz $=\operatorname{sqrt}\left(\right.$ left_upleg_a_x^2 + left_upleg_a_y $y^{\wedge} 2+$ left_upleg_a_z^ 2$)$,

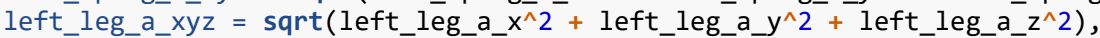

left_foot_a $x y z=\operatorname{sqrt}($ left_foot_a_x^2 + left_foot_a_y^2 + left_foot_a_z^2),

right_shoulder_a_xyz = sqrt (right_shoulder_a_- $\mathbf{x}^{\wedge} 2+$ right_shoulder_a_ $\bar{y}^{\wedge} \overline{2}+$ right_shoulder_a_z^ 2$)$,

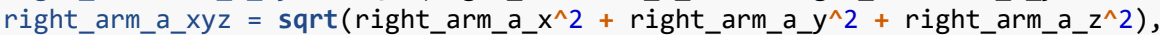

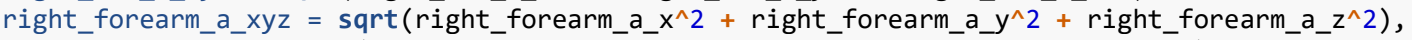
right_hand_a_xyz $=\operatorname{sqrt}\left(\right.$ right_hand_a_ $x^{\wedge} 2+$ right_hand_a_ $y^{\wedge} 2+$ right_hand_a_z^ 2 ),

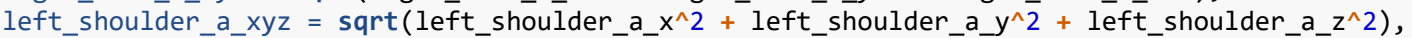
left_arm_a_xyz = sqrt (left_arm_a_x^2 + left_arm_a_y^2 + left_arm_a_z^2),

left_forearm_a_xyz $=\operatorname{sqrt}\left(\bar{l}\right.$ eft_forearm_a_x $x^{\wedge} \overline{2}+\bar{l}$ eft_forearm_a_y^${ }^{\wedge} \overline{2}+$ left_forearm_a_z^ 2$)$,

left_hand_a_xyz $=\operatorname{sqrt}($ left_hand_a_x^2 + left_hand_a_y^ $2+$ left_hand_a_z^ 2 ),

head_a_xyz $=\operatorname{sqrt}\left(\right.$ head_a_ $x^{\wedge} \overline{2}+$ head_a_y^ $2+$ head_a_z^ 2$)$,

neck_a_xyz $=\operatorname{sqrt}($ neck_a_x^2 + neck_a_y^2 + neck_a_z^ 2$)$,

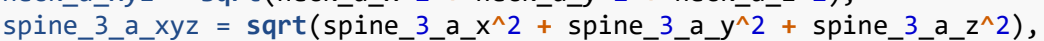

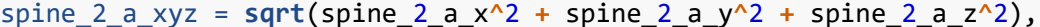

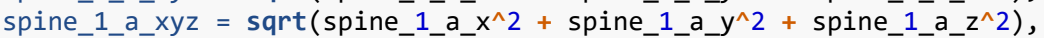

spine_a_xyz $=\operatorname{sqrt}\left(\right.$ spine_a_ $x^{\wedge} 2+$ spine_a_y^ $2+$ spine_a_z $\left.z^{\wedge} 2\right)$,

\# for velocity

hips_v_xyz $=\operatorname{sqrt}\left(\right.$ hips_v_ $x^{\wedge} 2+$ hips_v_y^2+ hips_v_z^ 2$)$,

right_upleg_v_xyz $=\operatorname{sqrt}(r i g h t$ upleg_v_x^2 + right_upleg_v_y^2+ right_upleg_v_z^2),

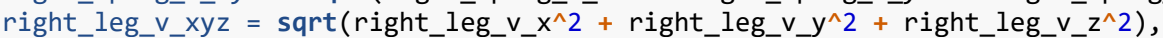

right_foot_v_xyz $=\operatorname{sqrt}\left(\right.$ right_foot_v_ $x^{\wedge} 2+$ right_foot_v_y^ $2+$ right_foot_v_z^ 2$)$,

left_upleg_v_xyz $=\operatorname{sqrt}($ left_upleg_v_t^2 + left_upleg_v_y^2 + left_upleg_v_z^2),

left_leg_v_xyz = sqrt(left_leg_v_x^2 + left_leg_v_y^2 + left_leg_v_z^2),

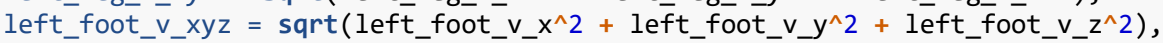

right_shoulder_v_xyz $=\operatorname{sgrt}\left(\right.$ right_shoulder_v__$x^{\wedge} 2+$ right_shoulder_v_ $\bar{y}^{\wedge} \overline{2}+$ right_shoulder_v_z^ 2$)$, right_arm_v_xyz $=\operatorname{sqrt}\left(r i g h t \_a r m \_v \_x^{\wedge} 2+r \bar{g} g h t \_a r m \_v \_y^{\wedge} 2+r i g h t \_a r m \_v \_z^{\wedge} 2\right)$,

right_forearm_v_xyz $=\operatorname{sqrt}\left(r \overline{i g h t} \_\right.$forearm_v_ $x^{\wedge} 2^{-}+$right_forearm_v_y^2+ right_forearm_v_z$\left.{ }^{\wedge} 2\right)$, right_hand_v_xyz $=\operatorname{sgrt}\left(\right.$ right_hand_v $x^{\wedge} 2^{-}+$right_hand_v $y^{\wedge} 2+\overline{r i g h t}$ hand_v_z$\left.z^{\wedge} 2\right)$,

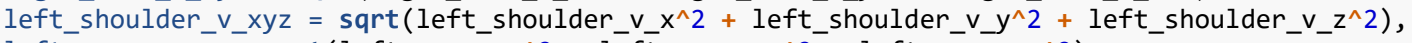

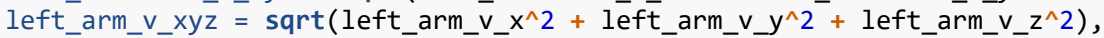

left_forearm_v_xyz = sqrt(left_forearm_v_x$x^{\wedge} 2+$ left_forearm_v_y^2 + left_forearm_v_z^2),

left_hand_v_xyz $=\operatorname{sqrt}\left(\right.$ left_hand_v_ $x^{\wedge} 2^{-}+$left_hand_v_y^ $2+\bar{l}$ eft_hand_v_z^ 2$)$,

head_v_xyz $=\operatorname{sqrt}\left(\right.$ head_v_x^ $2+$ head_v_y^^ $2+$ head_v_z $\left.z^{\wedge} 2\right)$,

neck_v_xyz $=\operatorname{sqrt}\left(\right.$ neck_v_ $x^{\wedge} 2+$ neck_v_y^2+ neck_v_z^2),

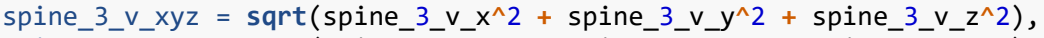

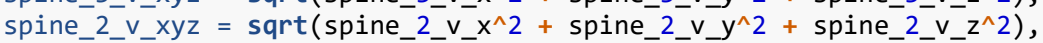

spine_1_v_xyz = sqrt (spine_1_v_ $x^{\wedge} 2+$ spine_1_v_y^2 + spine_1_v_z^2),

spine_v_xyz $=\operatorname{sqrt}\left(\right.$ spine_v_ $x^{\wedge} 2^{-}+$spine_v_y^2+ spine_v_z^ 2$)$,

\# for smooth acceleration

hips_a_xyz_smooth $=$ as.numeric(signal::filter(x=hips_a_xyz, filt=bf)),

right_upleg_a_xyz_smooth = as.numeric(signal::filter $(x=$ right_upleg_a_xyz, filt $=b f)$ ),

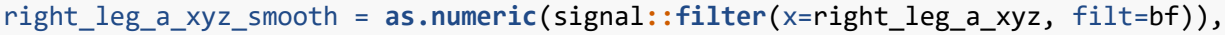

right_foot_a_xyz_smooth = as.numeric(signal::filter $(x=r i g h t$

left_upleg_a_xyz_smooth $=$ as.numeric(signal::filter $\left(x=l e f t \_u p l e g \_a \_x y z, f i l t=b f\right)$ ),

left_leg_a_xyz_smooth $=$ as.numeric (signal: :filter $(x=l$ left_leg_a_xyz, filt=bf)),

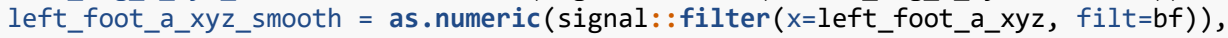

right_shoulder_a_xyz_smooth = as.numeric(signal::filter $(x=r i g h t$

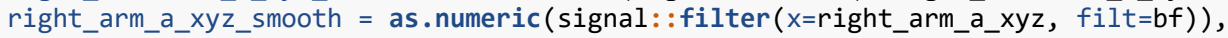

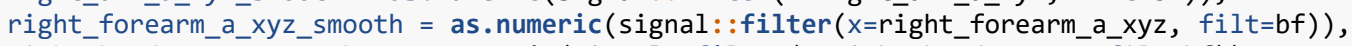
right_hand_a_xyz_smooth $=$ as.numeric(signal::filter $(x=$ right_hand_a_xyz, filt=bf)),

left_shoulder_a_xyz_smooth = as.numeric(signal: :filter $(x=l$ eft_shoulder_a_xyz, filt=bf)), left_arm_a_xyz_smooth $=$ as.numeric(signal::filter(x=left_arm_a_xyz, filt $=b f)$ ),

left_forearm_a_xyz_smooth $=$ as.numeric(signal: $:$ filter $(x=\bar{l}$ eft_forearm_a_xyz, filt $=b f)$ ),

left_hand_a_xyz_smooth $=$ as.numeric(signal::filter $(x=l$ left_hand_a_xyz, filt=bf $)$ ),

head_a_xyz_smooth = as.numeric(signal::filter( $\left.\left.x=h e a d \_a \_x y \bar{z}, f i \bar{l} t=b f\right)\right)$,

neck_a_xyz_smooth $=$ as.numeric $\left(\operatorname{signal}:\right.$ :filter $\left.\left(x=n e c k \_a \_x y z, f i l t=b f\right)\right)$, 
spine_3_a_xyz_smooth = as.numeric(signal::filter( $=$ spine_3_a_xyz, filt=bf)),

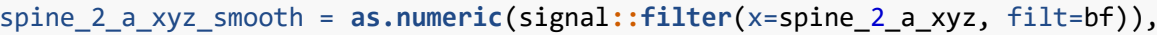

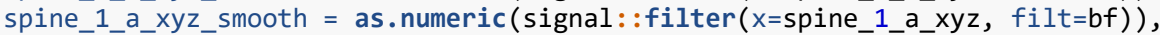
spine_a_xyz_smooth $=$ as.numeric $(\operatorname{signal}: \operatorname{filter}(x=\operatorname{spine} a$ _xyz, filt $=b f))$,

\# for smooth velocity

hips_v_xyz_smooth $=$ as.numeric(signal: :filter(x=hips_v_xyz, filt=bf)),

right_upleg_v_xyz_smooth = as.numeric(signal: :filter $(x=$ right_upleg_v_xyz, filt=bf)), right_leg_v_xyz_smooth $=$ as.numeric (signal: :filter $\left(x=r i g h t \_l e g \_v \_x y z\right.$, filt $\left.=b f\right)$ ), right_foot_v_xyz_smooth = as.numeric(signal: :filter(x=right_foot_v_xyz, filt=bf)), left_upleg_v_xyz_smooth $=$ as.numeric(signal: :filter $\left.\left(x=l e f t \_u p l e g \_v \_x y z, f i l t=b f\right)\right)$, left_leg_v_xyz_smooth $=$ as.numeric(signal: :filter $\left(x=l e f t \_l e g \_v \_x y z, f i l t=b f\right)$ ),

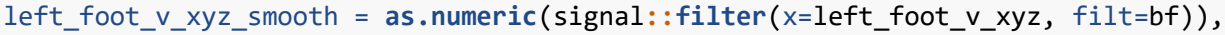

right_shoulder_v_xyz_smooth $=$ as.numeric(signal: :filter $(x=r i g h t$ shoulder_v_xyz, filt=bf)),

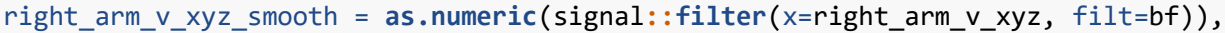

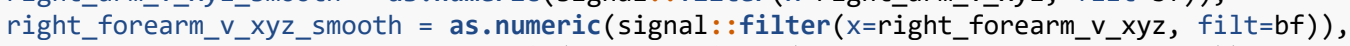
right_hand_v_xyz_smooth = as.numeric(signal::filter(x=right_hand_v_xyz, filt=bf)), left_shoulder_v_xyz_smooth $=$ as.numeric(signal: :filter $(x=l e f t$ _shoulder_v_xyz, filt $=b f)$ ), left_arm_v_xyz_smooth $=$ as.numeric(signal: :filter(x=left_arm_v_xyz, filt=bf)), left_forearm_v_xyz_smooth = as.numeric(signal: :filter $(x=\bar{l}$ eft_forearm_v_xyz, filt=bf)), left_hand_v_xyz_smooth $=$ as.numeric (signal: :filter $(x=l$ eft_hand_v_xyz, filt=bf $)$ ), head_v_xyz_smooth $=$ as.numeric(signal::filter $\left(x=h e a d \_v \_x y z, f i \bar{t}=b f\right)$ ), neck_v_xyz_smooth $=$ as.numeric(signal::filter $(x=$ neck_v_xyz, filt=bf)), spine_3_v_xyz_smooth $=$ as.numeric(signal: :filter $\left(x=s p i n e \_3 \_v \_x y z\right.$, filt $\left.=b f\right)$ ), spine_2_v_xyz_smooth $=$ as.numeric (signal: :filter $\left(x=s p i n e \_2 \_v \_x y z\right.$, filt $\left.=b f\right)$ ), spine_1_v_xyz_smooth $=$ as.numeric(signal: $:$ filter $\left(x=s p i n e \_1 \_v \_x y z\right.$, filt $\left.=b f\right)$ ), spine_v_xyz_smooth $=$ as.numeric (signal::filter $\left(x=s p i n e \_v \_x y z\right.$, filt $\left.=b f\right)$ ),

\# for smooth spatial displacement

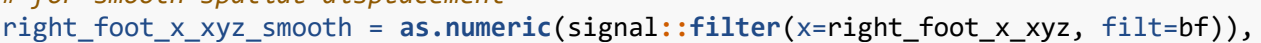

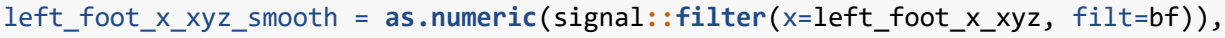
right_foot_z_xy_smooth $=$ as.numeric (signal: $:$ filter $(x=r i g h t$ left_foot_x_xy_smooth $=$ as.numeric(signal: :filter $(x=l$ eft_foot_x_xy, filt=bf)), right_foot_x_z_smooth $=$ as.numeric (signal: :filter $(x=r i g h t$ left_foot_x_z_smooth = as.numeric(signal: :filter(x=left_foot_x_z, filt=bf)),

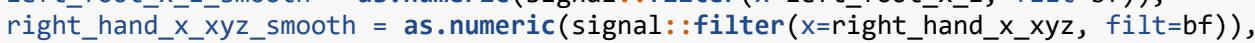
left_hand_x_xyz_smooth $=$ as.numeric (signal: :filter $(x=l e f t$ hand_x_xyz, filt=bf)),

\# detect gait-parts based on foot-velocity

diff_left_right_foot = as.numeric(left_foot_v_xyz_smooth) - as.numeric(right_foot_v_xyz_smooth),

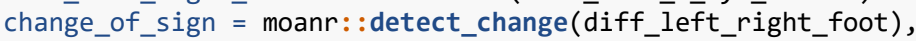

\# add Location of peaks

peaks_hips_a = moanr::find_peaks(hips_a_xyz_smooth), peaks_right_foot_a = moanr: :find_peaks (right_foot_a_xyz_smooth), peaks_left_foot_a $=$ moanr: :find_peaks (left_foot_a_xyz_smooth), peaks_right_hand_a = moanr: :find_peaks (right_hand_a_xyz_smooth), peaks_left_hand_a $=$ moanr: :find_peaks (left_hand_a_xyz_smooth),

peaks_hips_v = moanr::find_peaks(hips_v_xyz_smooth), peaks_right_foot_v = moanr: :find_peaks (right_foot_v_xyz_smooth), peaks_left_foot_v = moanr: :find_peaks (left_foot_v_xyz_smooth), peaks_right_hand_v = moanr: :find_peaks (right_hand_v_xyz_smooth), peaks_left_hand_v $=$ moanr: :find_peaks (left_hand_v_xyz_smooth),

\# add minima for hands

minima left hand $v=$ moanr: : find minima(left hand $v$ xyz smooth), minima_right_hand_v = moanr: :find_minima(right_hand_v_xyz_smooth)

)

if (batch) \{

output <- output \% $\%$

dplyr::mutate(subject_id = id,

diagnosis = dplyr: :case_when(

stringr::str_detect(string = subject_id, pattern $=$ "[ABCDE][012]") "control", stringr::str_detect(string $=$ subject_id, pattern $=$ "[FGHIJ][012]") "asd", 


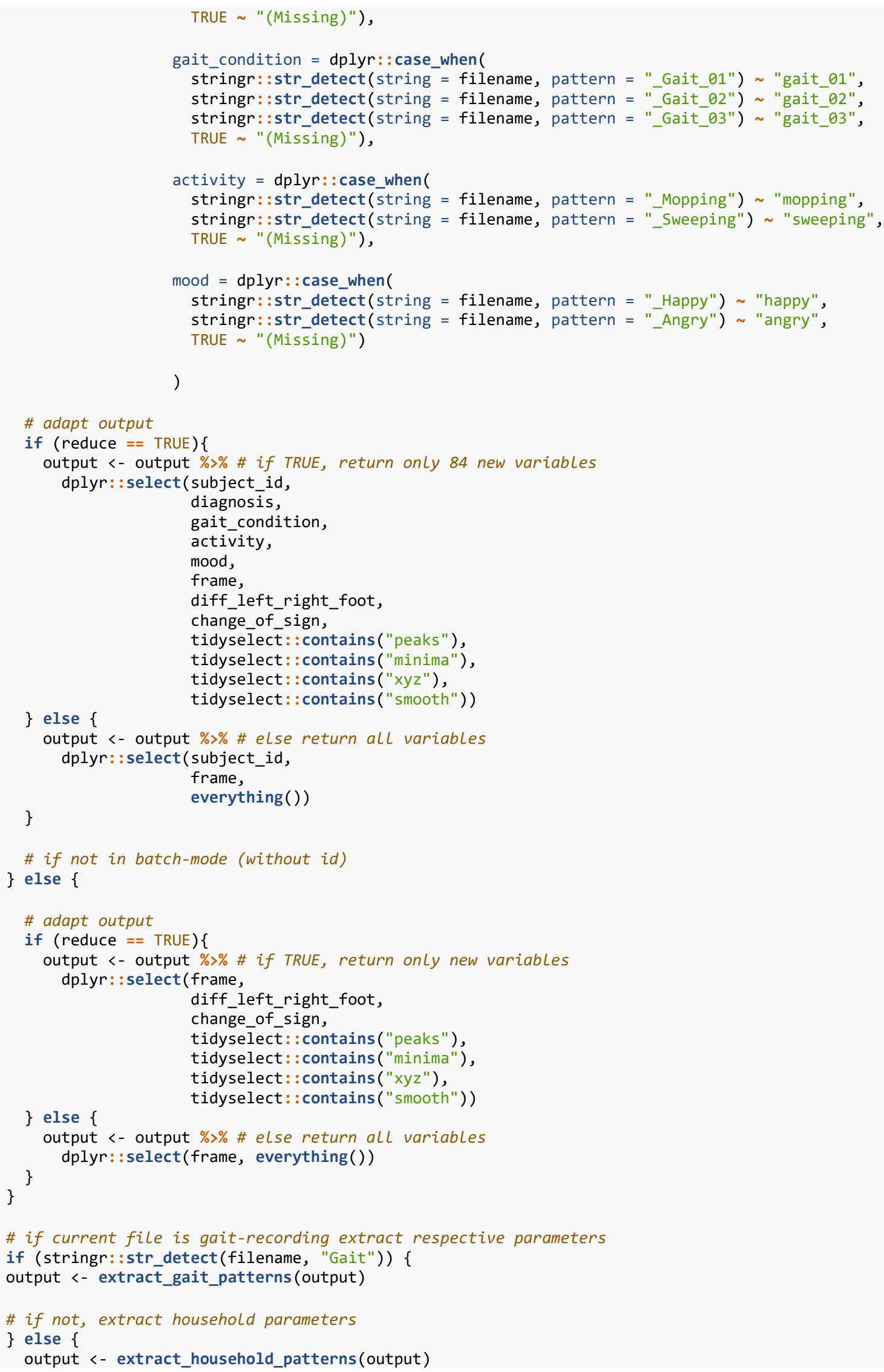


\}

output

\}

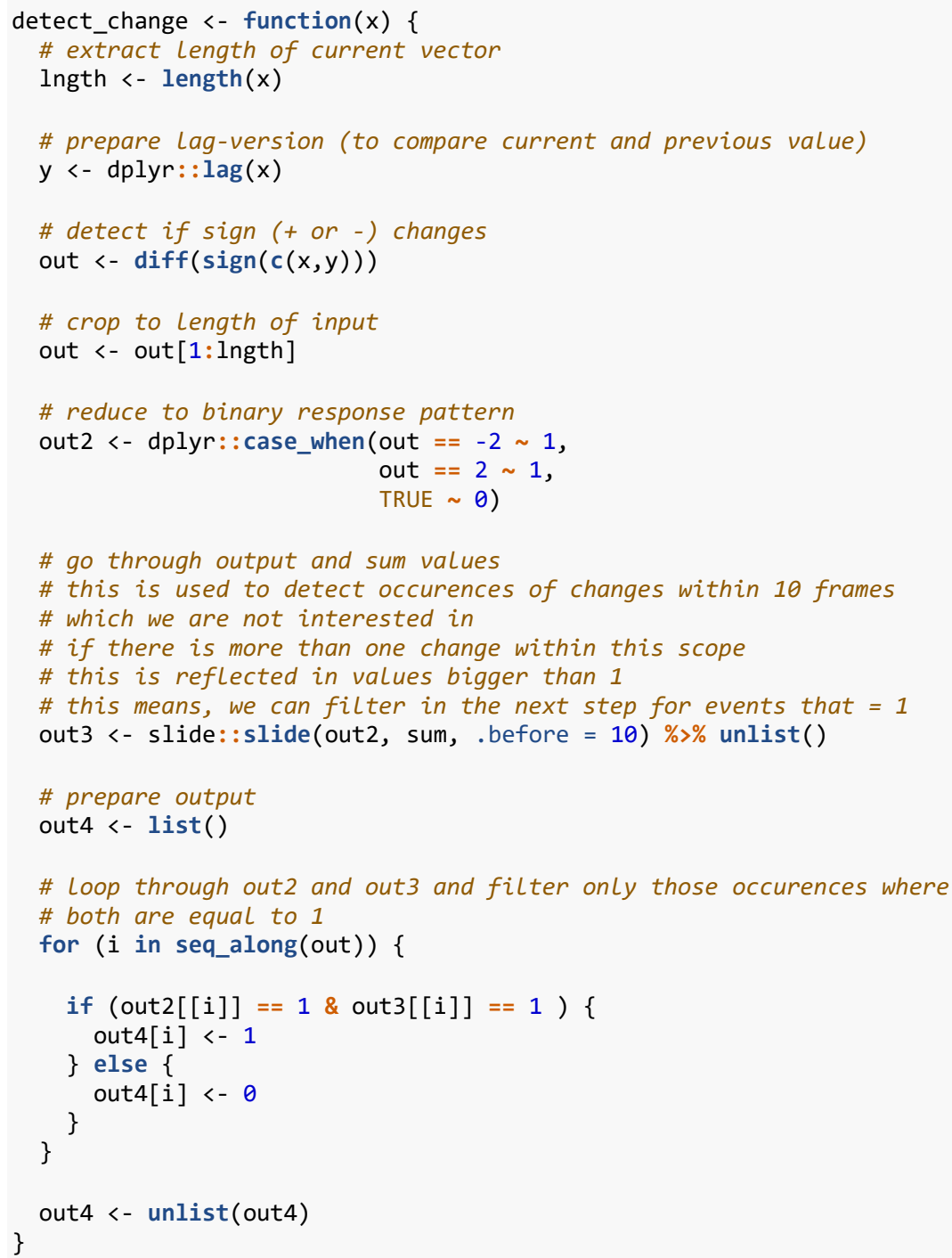




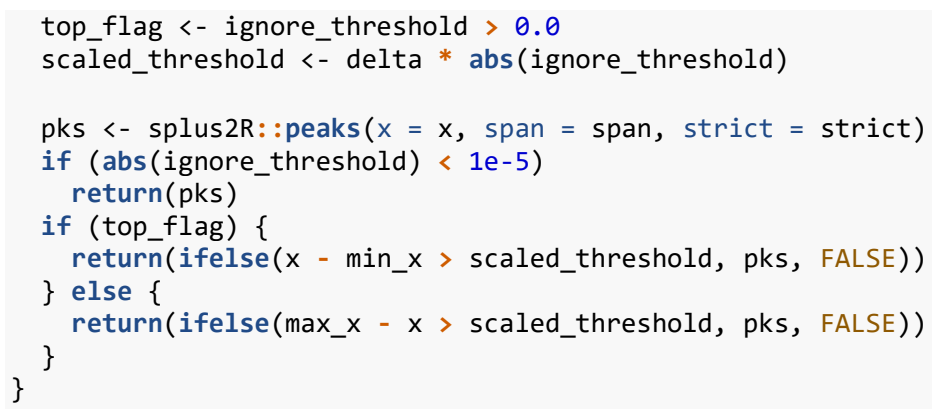




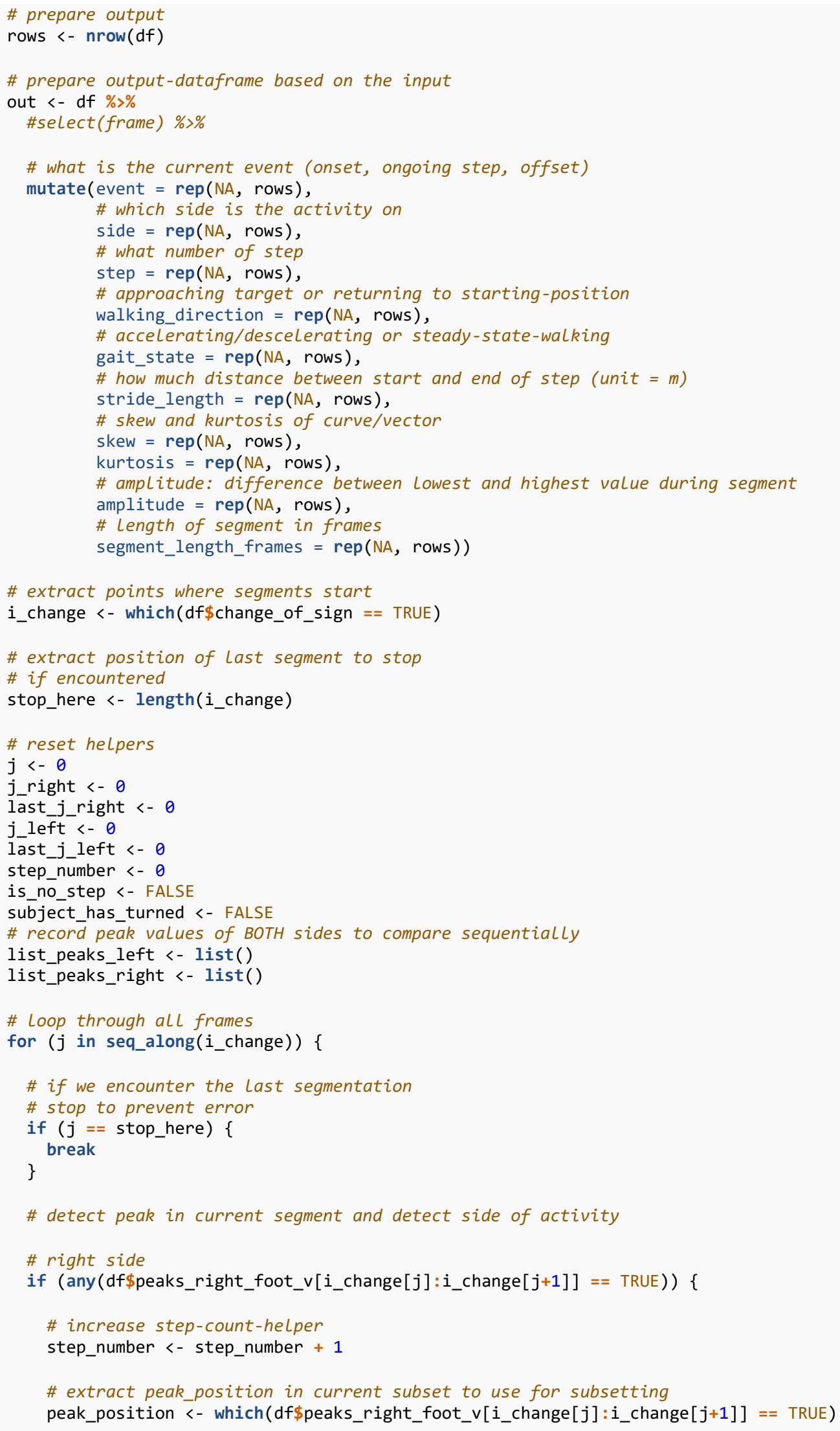




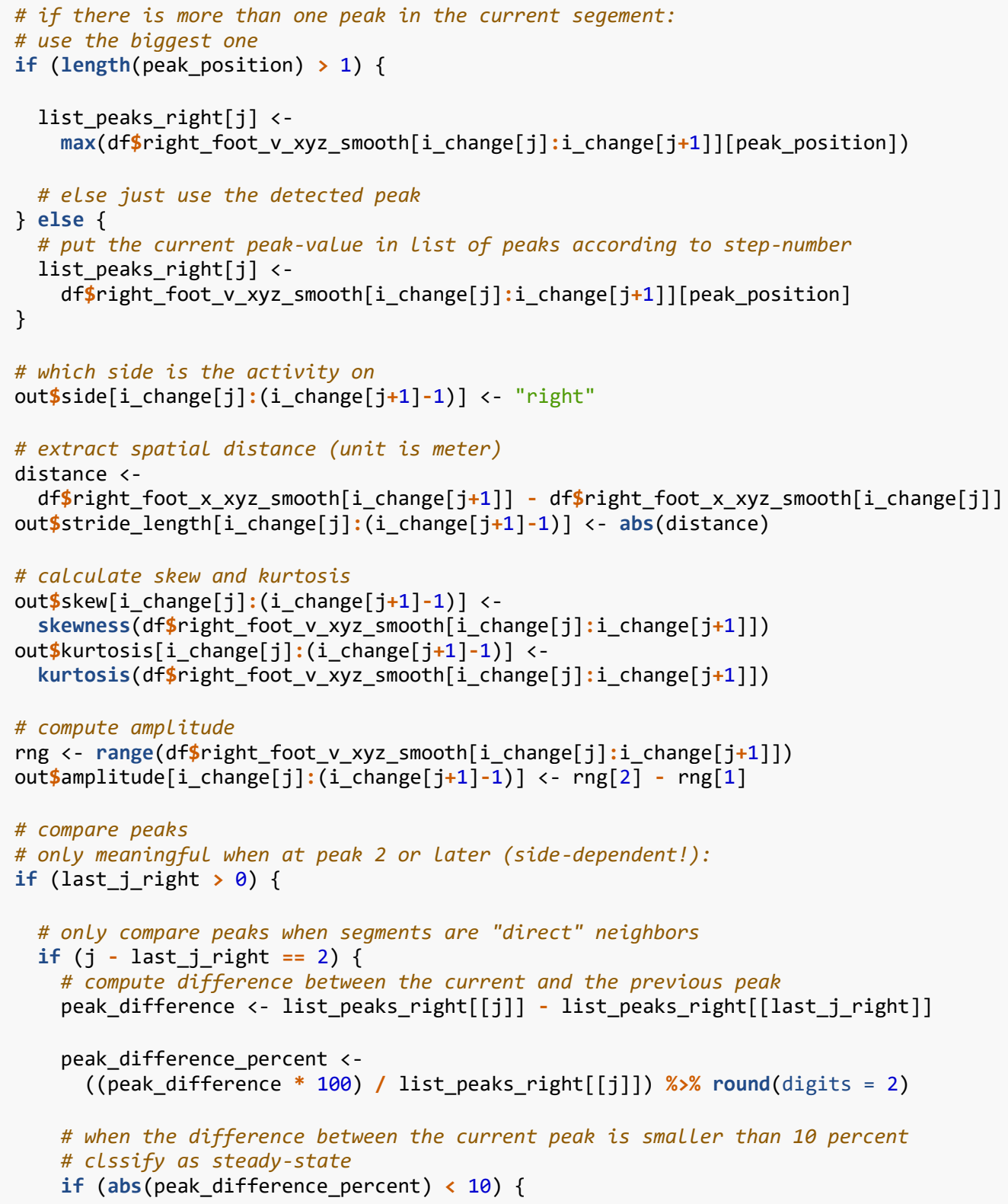




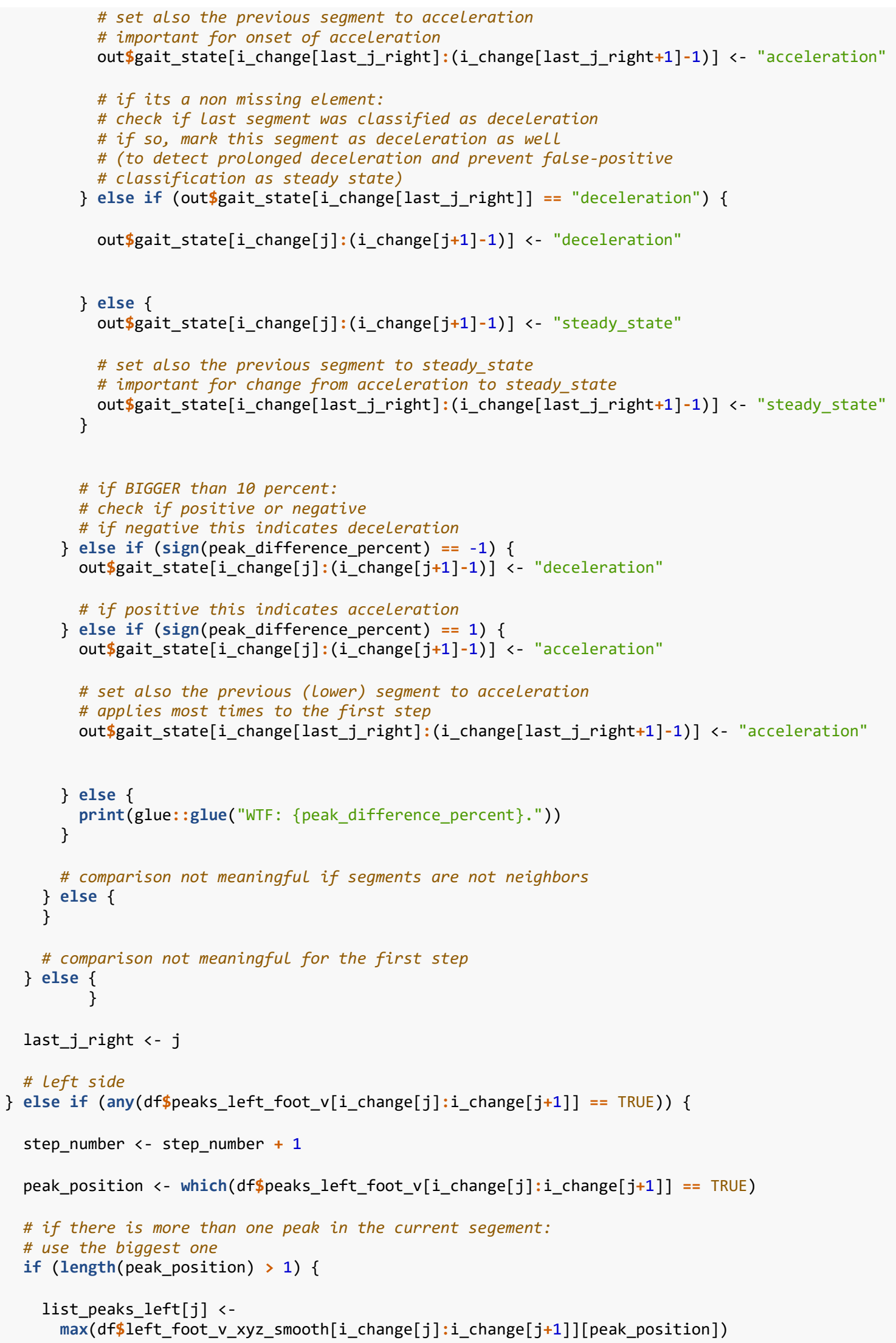




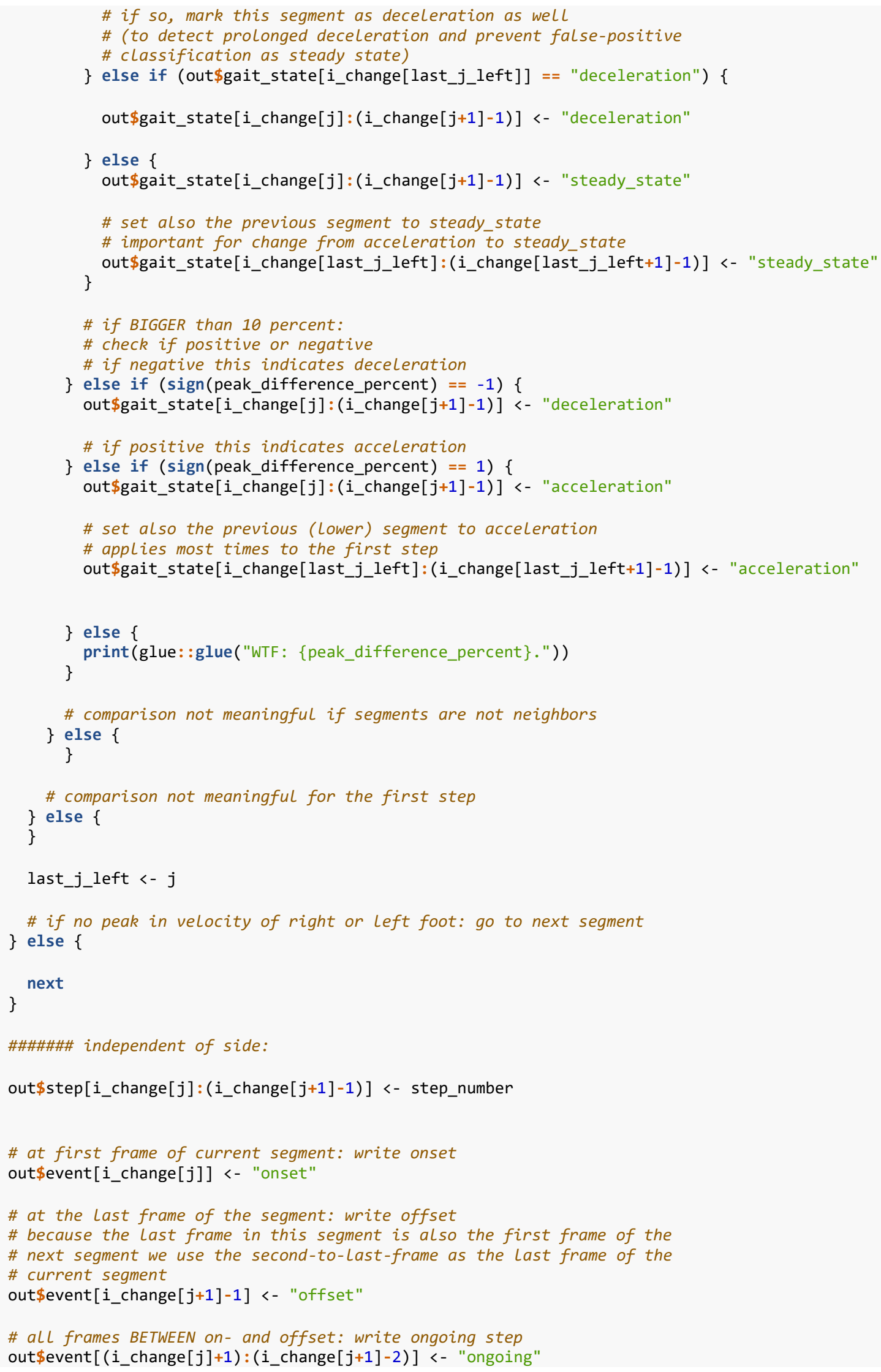




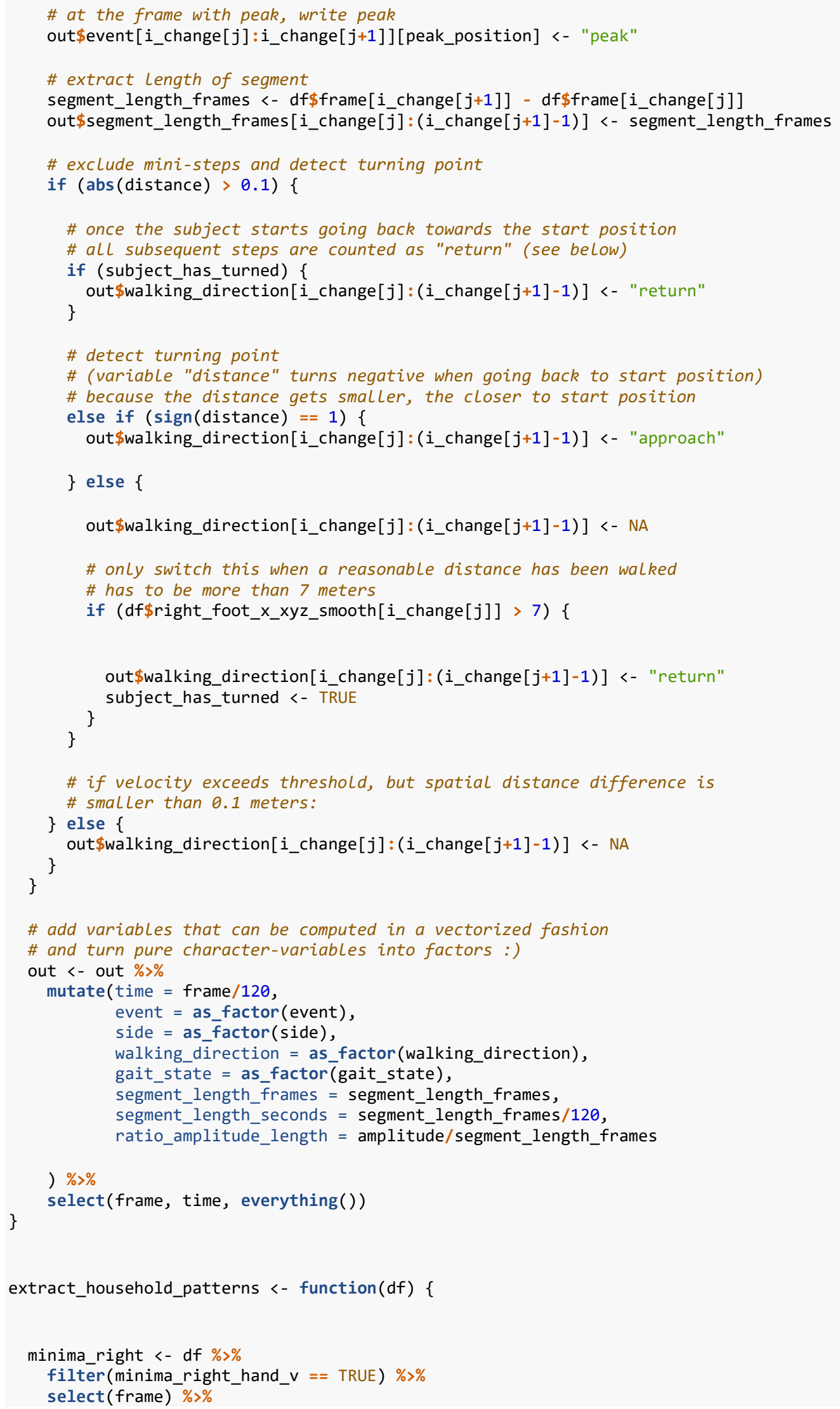




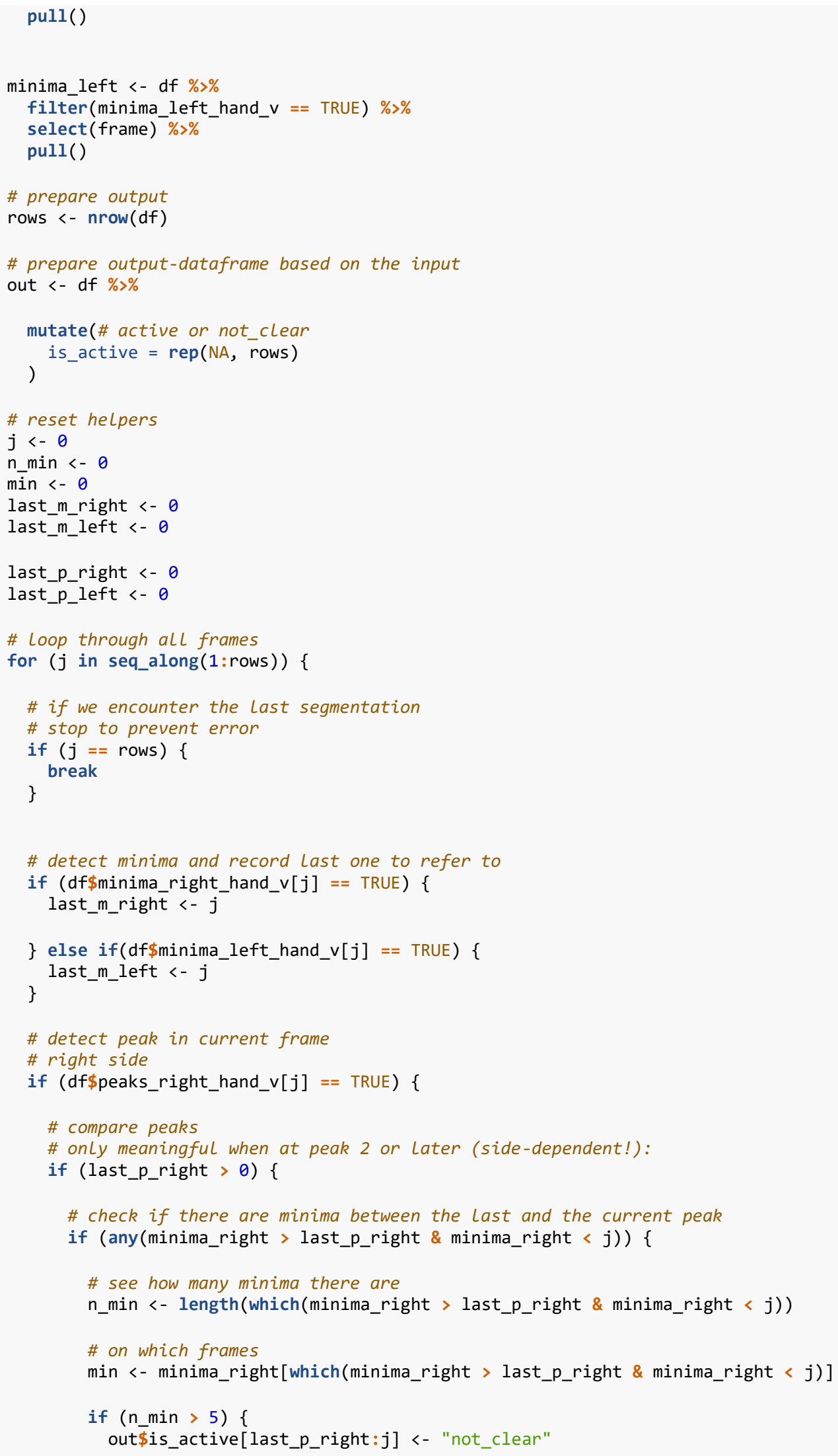




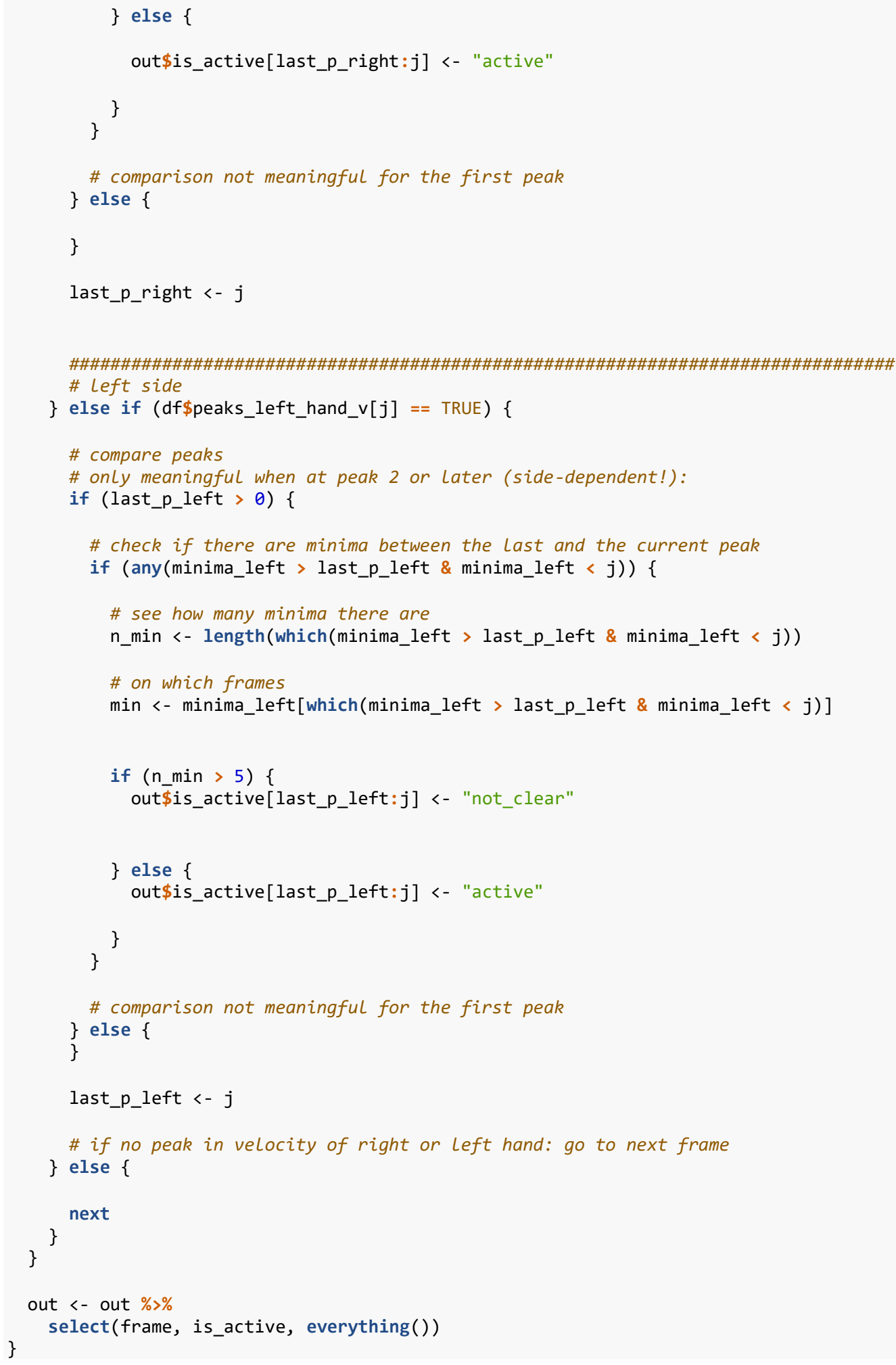




\section{Appendix B: Model Parameters}

As outlined in section 5.1.2, models were compared using likelihood ratio tests, starting with a model containing only the intercept (denoted "Null" in the tables below). All models contained random intercepts for participants. After determining which main-effects-model fit the data best, it was tested if a model containing interaction terms between the main effects fit the data better (see Table B2 for an example). Model results are displayed only for the model that fit the data best. The full model formula of that respective model is given under each model results table (see e.g. Table B3).

\section{Experiment One: Gait}

\section{Stride Length}

Table B1 Model Selection: Stride Length (Main Effects)

\begin{tabular}{lccllll}
\hline Model & df & AIC & BIC & statistic & Chi.Df & p.value \\
\hline Null & 3 & 1961 & 1980 & NA & NA & NA \\
+ walking_direction & 4 & 1954 & 1979 & 9.26 & 1 & 0.002 \\
+ gait_condition & 6 & 1950 & 1988 & 7.41 & 2 & 0.025 \\
+ diagnosis & 7 & 1948 & 1992 & 3.71 & 1 & 0.054 \\
\hline
\end{tabular}

Table B2 Model Selection: Stride Length (Interaction Effects)

\begin{tabular}{ccccccl}
\hline \multicolumn{1}{c}{ Model } & df & AIC & BIC & statistic & Chi.Df & p.value \\
\hline walking_direction + gait_condition & 6 & 1950 & 1988 & NA & NA & NA \\
walking_direction * gait_condition & 8 & 1948 & 1998 & 5.92 & 2 & 0.052 \\
\hline
\end{tabular}


Table B3 Model Results: Stride Length ${ }^{a}$

\begin{tabular}{lclll}
\hline \multicolumn{1}{c}{ Variable } & estimate & std.error & statistic & p.value \\
\hline (Intercept) & 1.05276 & 0.01608 & 65.472 & $<0.001$ \\
walking_direction_return & -0.02991 & 0.00976 & -3.065 & 0.008 \\
gait_condition_02 & -0.03135 & 0.01190 & -2.635 & 0.032 \\
gait_condition_03 & -0.00833 & 0.01194 & -0.698 & 0.914 \\
\hline
\end{tabular}

${ }^{\mathrm{a} F u l l ~ m o d e l ~ f o r m u l a: ~}$

stride_length $\sim$ walking_direction + gait_condition $+(1 \mid$ subject_id $)$ 


\section{Stride Time}

Table B4 Model Selection: Stride Time (Main Effects)

\begin{tabular}{lllllll}
\hline Model & df & AIC & BIC & statistic & Chi.Df & p.value \\
\hline Null & 3 & 29740 & 29758 & NA & NA & NA \\
+ walking_direction & 4 & 29736 & 29761 & 5.48 & 1 & 0.019 \\
+ gait_condition & 6 & 29714 & 29751 & 26.20 & 2 & $<0.001$ \\
+ diagnosis & 7 & 29715 & 29759 & 1.03 & 1 & 0.311 \\
\hline
\end{tabular}

Table B5 Model Selection: Stride Time (Interaction Effects)

\begin{tabular}{lllllll}
\hline Model & df & AIC & BIC & statistic & Chi.Df & p.value \\
\hline walking_direction + gait_condition & 6 & 29714 & 29751 & NA & NA & NA \\
walking_direction * gait_condition & 8 & 29717 & 29767 & 1.27 & 2 & 0.531 \\
\hline
\end{tabular}

Table B6 Model Results: Stride Time ${ }^{a}$

\begin{tabular}{lllll}
\hline Variable & estimate & std.error & statistic & p.value \\
\hline (Intercept) & 64.361 & 0.770 & 83.60 & $<0.001$ \\
walking_direction_return & 0.786 & 0.329 & 2.39 & 0.063 \\
gait_condition_02 & 1.708 & 0.402 & 4.25 & $<0.001$ \\
gait_condition_03 & 1.847 & 0.403 & 4.58 & $<0.001$ \\
\hline
\end{tabular}

${ }^{\mathrm{a}}$ Full model formula:

stride_time $\sim$ walking_direction + gait_condition $+(1 \mid$ subject_id $)$ 


\section{Velocity Left Foot}

Table B7 Model Selection: Velocity Left Foot (Main Effects)

\begin{tabular}{lllllll}
\hline Model & df & AIC & BIC & statistic & Chi.Df & p.value \\
\hline Null & 3 & 909206 & 909238 & NA & NA & NA \\
+ walking_direction & 4 & 909191 & 909233 & 17.5 & 1 & $<0.001$ \\
+ gait_condition & 6 & 909104 & 909167 & 90.5 & 2 & $<0.001$ \\
+ diagnosis & 9 & 909099 & 909193 & 10.9 & 3 & 0.012 \\
\hline
\end{tabular}

Table B8 Model Selection: Velocity Left Foot (Interaction Effects)

\begin{tabular}{lllllll}
\hline Model & df & AIC & BIC & statistic & Chi.Df & p.value \\
\hline walking_direction + gait_condition & 6 & 909104 & 909167 & NA & NA & NA \\
walking_direction * gait_condition & 8 & 909100 & 909184 & 8.33 & 2 & 0.016 \\
\hline
\end{tabular}

Table B9 Model Results: Velocity Left Foot ${ }^{\mathrm{a}}$

\begin{tabular}{lllll}
\hline Variable & estimate & std.error & statistic & p.value \\
\hline (Intercept) & 1.2119 & 0.01998 & 60.65 & $<0.001$ \\
walking_direction_return & -0.0213 & 0.00945 & -2.25 & 0.109 \\
gait_condition_02 & -0.0686 & 0.00952 & -7.20 & $<0.001$ \\
gait_condition_03 & -0.0358 & 0.00957 & -3.74 & $<0.001$ \\
walking_direction_return:gait_condition_02 & 0.0161 & 0.01336 & 1.21 & 0.670 \\
walking_direction_return:gait_condition_03 & -0.0224 & 0.01340 & -1.67 & 0.352 \\
\hline
\end{tabular}

${ }^{\mathrm{a}}$ Full model formula:

left_foot_vel walking_direction * gait_condition + (1 | subject_id $)$ 


\section{Velocity Right Foot}

Table B10 Model Selection: Velocity Right Foot (Main Effects)

\begin{tabular}{lllllll}
\hline Model & df & AIC & BIC & statistic & Chi.Df & p.value \\
\hline Null & 3 & 922912 & 922944 & NA & NA & NA \\
+ gait_condition & 5 & 922713 & 922765 & 203.80 & 2 & $<0.001$ \\
+ diagnosis & 6 & 922710 & 922773 & 4.89 & 1 & 0.027 \\
+ walking_direction & 7 & 922708 & 922782 & 3.47 & 1 & 0.063 \\
\hline
\end{tabular}

Table B11 Model Selection: Velocity Right Foot (Interaction Effects)

\begin{tabular}{lllllll}
\hline Model & df & AIC & BIC & statistic & Chi.Df & p.value \\
\hline diagnosis + gait_condition & 6 & 922710 & 922773 & NA & NA & NA \\
diagnosis * gait_condition & 8 & 922711 & 922794 & 3.14 & 2 & 0.208 \\
\hline
\end{tabular}

Table B12 Model Results: Velocity Right Foot ${ }^{a}$

\begin{tabular}{lccll}
\hline Variable & estimate & std.error & statistic & p.value \\
\hline (Intercept) & 1.2869 & 0.02343 & 54.94 & $<0.001$ \\
diagnosisasd & -0.0900 & 0.03949 & -2.28 & 0.082 \\
gait_condition_02 & -0.0882 & 0.00686 & -12.87 & $<0.001$ \\
gait_condition_03 & -0.0810 & 0.00688 & -11.78 & $<0.001$ \\
\hline
\end{tabular}

${ }^{\mathrm{a} F u l l ~ m o d e l ~ f o r m u l a: ~}$

right_foot_vel $\sim$ diagnosis + gait_condition + (1 | subject_id $)$ 


\section{Acceleration Right Foot}

Table B13 Model Selection: Acceleration Right Foot (Main Effects)

\begin{tabular}{lllllll}
\hline Model & df & AIC & BIC & statistic & Chi.Df & p.value \\
\hline Null & 3 & 648434 & 648466 & NA & NA & NA \\
+ walking_direction & 4 & 648385 & 648426 & 51.72 & 1 & $<0.001$ \\
+ gait_condition & 6 & 648134 & 648197 & 254.58 & 2 & $<0.001$ \\
+ diagnosis & 7 & 648134 & 648208 & 1.71 & 1 & 0.191 \\
\hline
\end{tabular}

Table B14 Model Selection: Acceleration Right Foot (Interaction Effects)

\begin{tabular}{lllllll}
\hline Model & df & AIC & BIC & statistic & Chi.Df & p.value \\
\hline walking_direction + gait_condition & 6 & 648134 & 648197 & NA & NA & NA \\
walking_direction * gait_condition & 8 & 648123 & 648207 & 14.8 & 2 & $<0.001$ \\
\hline
\end{tabular}

Table B15 Model Results: Acceleration Right Foot ${ }^{a}$

\begin{tabular}{lllll}
\hline Variable & estimate & std.error & statistic & p.value \\
\hline (Intercept) & 1.69272 & 0.01936 & 87.415 & $<0.001$ \\
walking_direction_return & -0.03659 & 0.00572 & -6.400 & $<0.001$ \\
gait_condition_02 & -0.07191 & 0.00576 & -12.479 & $<0.001$ \\
gait_condition_03 & -0.05885 & 0.00579 & -10.157 & $<0.001$ \\
walking_direction_return:gait_condition_02 & 0.02987 & 0.00808 & 3.696 & 0.001 \\
walking_direction_return:gait_condition_03 & 0.00731 & 0.00811 & 0.902 & 0.867 \\
\hline
\end{tabular}

${ }^{\mathrm{a}}$ Full model formula:

right_foot_acc $\sim$ walking_direction * gait_condition $+(1 \mid$ subject_id $)$ 


\section{Acceleration Left Foot}

Table B16 Model Selection: Acceleration Left Foot (Main Effects)

\begin{tabular}{lllllll}
\hline Model & df & AIC & BIC & statistic & Chi.Df & p.value \\
\hline Null & 3 & 655067 & 655098 & NA & NA & NA \\
+ walking_direction & 4 & 655032 & 655074 & 37.01 & 1 & $<0.001$ \\
+ gait_condition & 6 & 654904 & 654967 & 132.14 & 2 & $<0.001$ \\
+ diagnosis & 7 & 654903 & 654976 & 2.97 & 1 & 0.085 \\
\hline
\end{tabular}

Table B17 Model Selection: Acceleration Left Foot (Interaction Effects)

\begin{tabular}{lllllll}
\hline Model & df & AIC & BIC & statistic & Chi.Df & p.value \\
\hline walking_direction + gait_condition & 6 & 654904 & 654967 & NA & NA & NA \\
walking_direction * gait_condition & 8 & 654899 & 654983 & 9 & 2 & 0.011 \\
\hline
\end{tabular}

Table B18 Model Results: Acceleration Left Foot ${ }^{a}$

\begin{tabular}{lcccc}
\hline Variable & estimate & std.error & statistic & p.value \\
\hline (Intercept) & 1.6686 & 0.02128 & 78.408 & $<0.001$ \\
walking_direction_return & -0.0144 & 0.00579 & -2.489 & 0.061 \\
gait_condition_02 & -0.0432 & 0.00584 & -7.393 & $<0.001$ \\
gait_condition_03 & -0.0285 & 0.00587 & -4.863 & $<0.001$ \\
walking_direction_return:gait_condition_02 & 0.0016 & 0.00819 & 0.195 & $>0.999$ \\
walking_direction_return:gait_condition_03 & -0.0205 & 0.00821 & -2.497 & 0.060 \\
\hline
\end{tabular}

${ }^{a}$ Full model formula:

left_foot_acc $\sim$ walking_direction * gait_condition $+(1 \mid$ subject_id $)$ 


\section{Experiment Two: Movement \& Mood}

\section{Velocity Right Hand}

Table B19 Model Selection: Velocity Right Hand (Main Effects)

\begin{tabular}{lllllll}
\hline Model & df & AIC & BIC & statistic & Chi.Df & p.value \\
\hline Null & 3 & 744029 & 744063 & NA & NA & NA \\
+ mood & 4 & 696269 & 696313 & 47762.8 & 1 & $<0.001$ \\
+ activity & 5 & 685419 & 685475 & 10851.4 & 1 & $<0.001$ \\
+ diagnosis & 6 & 685406 & 685472 & 15.7 & 1 & $<0.001$ \\
\hline
\end{tabular}

Table B20 Model Selection: Velocity Right Hand (Interaction Effects)

\begin{tabular}{lllllll}
\hline Model & df & AIC & BIC & statistic & Chi.Df & p.value \\
\hline mood + activity + diagnosis & 6 & 685406 & 685472 & NA & NA & NA \\
mood * activity * diagnosis & 10 & 683090 & 683201 & 2324 & 4 & $<0.001$ \\
\hline
\end{tabular}

Table B21 Model Results: Velocity Right Hand ${ }^{a}$

\begin{tabular}{lllll}
\hline Variable & estimate & std.error & statistic & p.value \\
\hline (Intercept) & 1.0110 & 0.03723 & 27.16 & $<0.001$ \\
mood_happy & -0.3123 & 0.00234 & -133.61 & $<0.001$ \\
activity_sweeping & 0.0974 & 0.00240 & 40.54 & $<0.001$ \\
diagnosis_ASD & -0.3385 & 0.06371 & -5.31 & $<0.001$ \\
mood_happy:activity_sweeping & 0.0431 & 0.00332 & 12.98 & $<0.001$ \\
mood_happy:diagnosis_ASD & 0.0503 & 0.00411 & 12.26 & $<0.001$ \\
activity_sweeping:diagnosis_ASD & 0.1788 & 0.00417 & 42.89 & $<0.001$ \\
mood_happy:activity_sweeping:diagnosis_ASD & -0.2092 & 0.00581 & -35.97 & $<0.001$ \\
\hline
\end{tabular}

${ }^{\mathrm{a}}$ Full model formula:

right_hand_vel $\sim \operatorname{mood} *$ activity $*$ diagnosis $+(1 \mid$ subject_id $)$ 


\section{Velocity Left Hand}

Table B22 Model Selection: Velocity Left Hand (Main Effects)

\begin{tabular}{lllllll}
\hline Model & df & AIC & BIC & statistic & Chi.Df & p.value \\
\hline Null & 3 & 692679 & 692712 & NA & NA & NA \\
+ mood & 4 & 642474 & 642519 & 50207 & 1 & $<0.001$ \\
+ activity & 5 & 633805 & 633861 & 8671 & 1 & $<0.001$ \\
+ diagnosis & 6 & 633793 & 633860 & 14 & 1 & $<0.001$ \\
\hline
\end{tabular}

Table B23 Model Selection: Velocity Left Hand (Interaction Effects)

\begin{tabular}{lllllll}
\hline Model & df & AIC & BIC & statistic & Chi.Df & p.value \\
\hline mood + activity + diagnosis & 6 & 633793 & 633860 & NA & NA & NA \\
mood * activity * diagnosis & 10 & 631822 & 631933 & 1979 & 4 & $<0.001$ \\
\hline
\end{tabular}

Table B24 Model Results: Velocity Left Hand ${ }^{a}$

\begin{tabular}{lllll}
\hline Variable & estimate & std.error & statistic & p.value \\
\hline (Intercept) & 1.0295 & 0.03823 & 26.93 & $<0.001$ \\
mood_happy & -0.3024 & 0.00222 & -136.21 & $<0.001$ \\
activity_sweeping & 0.0854 & 0.00228 & 37.42 & $<0.001$ \\
diagnosis_ASD & -0.3301 & 0.06542 & -5.05 & $<0.001$ \\
mood_happy:activity_sweeping & 0.0260 & 0.00315 & 8.24 & $<0.001$ \\
mood_happy:diagnosis_ASD & 0.0572 & 0.00390 & 14.66 & $<0.001$ \\
activity_sweeping:diagnosis_ASD & 0.1610 & 0.00396 & 40.64 & $<0.001$ \\
mood_happy:activity_sweeping:diagnosis_ASD & -0.1801 & 0.00552 & -32.61 & $<0.001$ \\
\hline
\end{tabular}

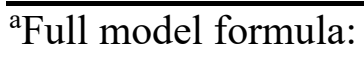

left_hand_vel $\sim \operatorname{mood} *$ activity $*$ diagnosis $+(1 \mid$ subject_id $)$ 


\section{Acceleration Right Hand}

Table B25 Model Selection: Acceleration Right Hand (Main Effects)

\begin{tabular}{lllllll}
\hline Model & df & AIC & BIC & statistic & Chi.Df & p.value \\
\hline Null & 3 & 1101899 & 1101933 & NA & NA & NA \\
+ mood & 4 & 1052266 & 1052310 & 49635.72 & 1 & $<0.001$ \\
+ activity & 5 & 1050213 & 1050268 & 2055.10 & 1 & $<0.001$ \\
+ diagnosis & 6 & 1050207 & 1050273 & 7.97 & 1 & 0.005 \\
\hline
\end{tabular}

Table B26 Model Selection: Acceleration Right Hand (Interaction Effects)

\begin{tabular}{lllllll}
\hline Model & df & AIC & BIC & statistic & Chi.Df & p.value \\
\hline mood + activity + diagnosis & 6 & 1050207 & 1050273 & NA & NA & NA \\
$\operatorname{mood} *$ activity * diagnosis & 10 & 1047972 & 1048083 & 2243 & 4 & $<0.001$ \\
\hline
\end{tabular}

Table B27 Model Results: Acceleration Right Hand ${ }^{a}$

\begin{tabular}{lcllc}
\hline Variable & estimate & std.error & statistic & p.value \\
\hline (Intercept) & 1.63453 & 0.04203 & 38.89 & $<0.001$ \\
mood_happy & -0.50460 & 0.00337 & -149.91 & $<0.001$ \\
activity_sweeping & 0.08585 & 0.00346 & 24.80 & $<0.001$ \\
diagnosis_ASD & -0.34794 & 0.07193 & -4.84 & $<0.001$ \\
mood_happy:activity_sweeping & -0.00517 & 0.00478 & -1.08 & 0.847 \\
mood_happy:diagnosis_ASD & 0.24722 & 0.00591 & 41.81 & $<0.001$ \\
activity_sweeping:diagnosis_ASD & 0.08721 & 0.00600 & 14.52 & $<0.001$ \\
mood_happy:activity_sweeping:diagnosis_ASD & -0.14119 & 0.00837 & -16.86 & $<0.001$ \\
\hline
\end{tabular}

${ }^{\mathrm{a}}$ Full model formula:

right_hand_acc $\sim \operatorname{mood} *$ activity $*$ diagnosis $+(1 \mid$ subject_id $)$ 


\section{Acceleration Left Hand}

Table B28 Model Selection: Acceleration Left Hand (Main Effects)

\begin{tabular}{lllllll}
\hline Model & df & AIC & BIC & statistic & Chi.Df & p.value \\
\hline Null & 3 & 1077298 & 1077331 & NA & NA & NA \\
+ mood & 4 & 1019921 & 1019965 & 57379.46 & 1 & $<0.001$ \\
+ activity & 5 & 1018947 & 1019003 & 975.28 & 1 & $<0.001$ \\
+ diagnosis & 6 & 1018941 & 1019007 & 8.72 & 1 & 0.003 \\
\hline
\end{tabular}

Table B29 Model Selection: Acceleration Left Hand (Interaction Effects)

\begin{tabular}{lllllll}
\hline Model & df & AIC & BIC & statistic & Chi.Df & p.value \\
\hline mood + activity + diagnosis & 6 & 1018941 & 1019007 & NA & NA & NA \\
$\operatorname{mood~*~activity~*~diagnosis~}$ & 10 & 1015342 & 1015453 & 3607 & 4 & $<0.001$ \\
\hline
\end{tabular}

Table B30 Model Results: Acceleration Left Hand ${ }^{a}$

\begin{tabular}{lclll}
\hline Variable & estimate & std.error & statistic & p.value \\
\hline (Intercept) & 1.70076 & 0.04165 & 40.8 & $<0.001$ \\
mood_happy & -0.56324 & 0.00326 & -172.9 & $<0.001$ \\
activity_sweeping & -0.00336 & 0.00335 & -1.0 & 0.888 \\
diagnosis_ASD & -0.42776 & 0.07128 & -6.0 & $<0.001$ \\
mood_happy:activity_sweeping & 0.06235 & 0.00462 & 13.5 & $<0.001$ \\
mood_happy:diagnosis_ASD & 0.31233 & 0.00572 & 54.6 & $<0.001$ \\
activity_sweeping:diagnosis_ASD & 0.21558 & 0.00581 & 37.1 & $<0.001$ \\
mood_happy:activity_sweeping:diagnosis_ASD & -0.24641 & 0.00811 & -30.4 & $<0.001$ \\
\hline
\end{tabular}

${ }^{\text {aFull model formula: }}$

left_hand_acc $\sim \operatorname{mood} *$ activity $*$ diagnosis $+(1 \mid$ subject_id $)$ 


\section{Declaration of Authorship}

I am aware of and understand the University's policy on plagiarism and I certify that this thesis is my own work, except where indicated by referencing, and that I have followed good academic practices.

Signed,

Sebastian Lammers, March 2020 